\title{
Alzheimer's disease pathology propagation by exosomes containing toxic amyloid-beta oligomers
}

\author{
Maitrayee Sardar Sinha ${ }^{1}$ Anna Ansell-Schultz ${ }^{1} \cdot$ Livia Civitelli $^{1}$ - Camilla Hildesjö ${ }^{1} \cdot$ Max Larsson $^{1} \cdot$ Lars Lannfelt $^{2,3}$. \\ Martin Ingelsson ${ }^{2} \cdot$ Martin Hallbeck $^{1}$ (i)
}

Received: 20 December 2017 / Revised: 15 May 2018 / Accepted: 19 May 2018 / Published online: 13 June 2018

(C) The Author(s) 2018

\begin{abstract}
The gradual deterioration of cognitive functions in Alzheimer's disease is paralleled by a hierarchical progression of amyloid-beta and tau brain pathology. Recent findings indicate that toxic oligomers of amyloid-beta may cause propagation of pathology in a prion-like manner, although the underlying mechanisms are incompletely understood. Here we show that small extracellular vesicles, exosomes, from Alzheimer patients' brains contain increased levels of amyloid-beta oligomers and can act as vehicles for the neuron-to-neuron transfer of such toxic species in recipient neurons in culture. Moreover, blocking the formation, secretion or uptake of exosomes was found to reduce both the spread of oligomers and the related toxicity. Taken together, our results imply that exosomes are centrally involved in Alzheimer's disease and that they could serve as targets for development of new diagnostic and therapeutic principles.
\end{abstract}

Keywords Alzheimer's disease $\cdot$ Exosomes $\cdot$ Oligomers $\cdot$ Beta-amyloid $\cdot$ Human $\cdot$ Prion-like $\cdot$ Propagation

\section{Introduction}

Gradual accumulation of toxic amyloid-beta $(\mathrm{A} \beta)$ and tau are believed to be central to Alzheimer's disease (AD) pathogenesis. These abnormal deposits typically appear with a hierarchical spatial distribution, which suggest that the pathological proteins can propagate between different brain areas [7, 52, 53]. Accordingly, recent studies have demonstrated transfer of $\mathrm{A} \beta$ in cellular and animal models [27,

Maitrayee Sardar Sinha and Anna Ansell-Schultz are equal contributors.

Electronic supplementary material The online version of this article (https://doi.org/10.1007/s00401-018-1868-1) contains supplementary material, which is available to authorized users.

Martin Hallbeck

Martin.Hallbeck@liu.se

1 Department of Pathology, Department of Clinical and Experimental Medicine, Linköping University, Linköping, Sweden

2 Department of Public Health and Caring Sciences, Geriatrics, Uppsala University, Uppsala, Sweden

3 BioArctic AB, Warfvinges väg 25, 11285 Stockholm, Sweden
$38-40,61]$ as well as spread of tau between neurons in the brain of transgenic mouse models [25]. These observations are further supported by the distribution of $A \beta$ and tau PET ligands in relation to the brain connectome [45].

Different $A \beta$ conformational states have different properties, and intermediate products of fibril formation, such as lower molecular weight $\mathrm{A} \beta$ oligomers (oA $\beta$ ) and protofibrils, have been suggested to be particularly neurotoxic and to act as seeds for further aggregation [27, 61]. In addition, these soluble forms of $\mathrm{A} ß$ correlate better than fibrils with cognitive function in the AD brain [39]. We have previously shown that oA $\beta$ can accumulate inside cells and subsequently spread from one cell to another $[15,40]$. These findings thus suggest that $\mathrm{A} \beta$ can propagate pathology in a manner similar to what is seen for prion disorders and for several other neurodegenerative diseases [8]. However, the underlying mechanisms for the spreading of toxic oA $\beta$ remain incompletely understood [28].

Exosomes, small extracellular vesicles (20-120 nm in diameter) [58] developing from endosomes through multivesicular bodies, have recently emerged as key players in cellular communication and transport of molecules in both health and disease, including neuronal toxicity [33] and neurodegenerative disorders [59]. Exosomes can carry different cargos such as proteins, RNA and miRNA and can also contain monomeric 
$\mathrm{A} \beta$, tau and $\alpha$-synuclein $[12,17,46,59]$ and can propagate tau pathology [4]. Thus, exosomes could potentially also carry aggregated proteins such as oAß. However, no study has so far investigated if exosomes isolated from $\mathrm{AD}$ brain tissue can be responsible for interneuronal protein transfer.

For the first time, we now demonstrate that intracellular $\mathrm{oA} \beta$ is co-localized with exosomes and show that AD brainderived exosomes can mediate neuron-to-neuron propagation of oAß. Furthermore, we show that the concentration of oA $\beta$ in exosomes is significantly increased in post mortem $\mathrm{AD}$ brains. In addition, exosomes carrying oA $\beta$ can be internalized in cultured neurons and spread their toxic content to nearby cells.

\section{Methods}

\section{Brain tissues}

Post mortem brain samples of temporal neocortex from healthy control ( 1 female, 4 male) and AD ( 4 female, 1 male) subjects (Table 1) were provided by the brain bank at Uppsala University, Sweden. The tissue was received as fresh-frozen or as formalin-fixed (4\% formaldehyde) paraffin-embedded blocks. The AD cases were neuropathologically diagnosed as CERAD C, Braak stages IV-VI. None of the control patients suffered from dementia or any neurodegenerative disorder. The collection and use of post mortem brain tissue was approved by the Regional Ethical Committee in Uppsala, Sweden (2005/103, 2005-06-29; 2009/089; 2009-04-22).

\section{Immunohistochemistry and immunofluorescence of brain sections}

Formalin-fixed, paraffin-embedded $10 \mu \mathrm{m}$ sections of temporal neocortex from healthy control and AD brains (Table 1) were used for this study and pretreated as previously described [6]. After 5 min blocking of endogenous peroxidase by incubation in Background Sniper (Biocare Medical), slides were washed in Tris-buffered saline (TBS) solution and incubated with rabbit polyclonal anti-flotillin-1 (Abcam, 1:200) followed by incubation with either the second primary mouse monoclonal antibody (mAb158, 1:7500, BioArctic) or mouse monoclonal antibody 82E1 (1:25, IBL International) for $30 \mathrm{~min}$ at room temperature (RT).

After rinsing in TBS, the slides were incubated for $30 \mathrm{~min}$ with MACH 2 Double Stain (Biocare Medical). Following this step, a 30 min incubation was performed with an AP linked chromogen IP Warp red/HRP linked chromogen Vina Green cocktail (Biocare Medical). After rinsing in deionized water, the sections were counterstained with Mayers haematoxylin (Histolab Products $\mathrm{AB}$ ) and mounted with Pertex mounting media (Histolab Products $\mathrm{AB}$ ) and micrographs were obtained using $100 \times$ oil immersion objective (Nikon Eclipse 80i, Digital Sight DS-Fi1).

After blocking and incubating with primary antibodies as described above, the slides were rinsed in TBS and incubated with a Fluorescence Enhancement Probe Mouse/ Fluorescence Enhancement Probe Rabbit cocktail (Biocare Medical) for $20 \mathrm{~min}$ subsequent to a $40 \mathrm{~min}$ incubation with a Goat-anti-Mouse DyLight 549/Goat Anti-Rabbit DyLight 488 cocktail (Biocare Medical) diluted 1:200, respectively. After rinsing in deionized water, the sections were nuclear counterstained with DAPI and mounted with Fluoro Care Anti-Fade Mountant (Biocare Medical) and analysed with a Zeiss LSM 700 confocal microscope. The differential interface contrast (DIC) mode and 405, 488, 555 and 639 lasers were used to acquire the images with $63 \mathrm{x} / 1.40$ oil immersion plan-apochromatic DICII objectives. The micrographs were processed using Huygens (Scientific Volume Imaging) and ZEN lite (blue edition) software.
Table 1 Demographic and clinical characteristics of post mortem cases used in the study

\begin{tabular}{lllllllll}
\hline Diagnosis & Age & Sex & PMI & Braak & Thal & CERAD & NIA-Reagan & $\alpha$ Syn \\
\hline AD & 61 & F & 48 & $5-6$ & 5 & C & High prob & None \\
AD & 64 & M & 12 & $5-6$ & 5 & C & High prob & None \\
AD & 85 & F & 21 & $5-6$ & 3 & B & High prob & None \\
AD & 90 & F & 11 & 5 & 3 & B & & None \\
AD & 63 & F & 48 & 6 & 5 & C & & None \\
C & 88 & M & 39 & 0 & 0 & 0 & & None \\
C & 88 & F & 22 & 2 & 0 & 0 & & In S Nigra \\
C & 63 & M & 30 & 0 & 0 & 0 & & None \\
C & 90 & M & 30 & 0 & 1 & 0 & & None \\
C & 91 & M & 27 & 3 & 4 & C & & None \\
\hline
\end{tabular}

5 severe Alzheimer's disease cases (Braak stages V-VI) and 5 nondemented cases (Braak stages 0-III) were used to determine the presence of oA $\beta$ in brain derived exosomes 


\section{Cell lines and differentiation}

Two different cultured cell types were used in the study: the human-induced pluripotent stem cells, AF22 (from a control subject) and the human neuroblastoma cell line, SH-SY5Y (ECACC: Sigma-Aldrich). The neuroepithelial stem cell line, $\mathrm{AF} 22$, derived from human-induced pluripotent stem cells from human skin fibroblasts was provided by Dr. Anna Falk, Karolinska Institute, Sweden. The process of reprogramming human cells was approved by the Ethical Committee at Karolinska Institute, Sweden (dnr 2012/208-31/3 with addendum 2012/856-32). All samples were given with informed consent. The AF22 cell line has previously been shown to have a stable neuronal differentiation competence and the capacity to generate functionally mature human neurons [20], denoted hiPSC. The hiPSCs were cultured on $0.01 \%$ poly-L-ornithine and laminin $(10 \mu \mathrm{g} / \mathrm{mL}$, SigmaAldrich) coated cell culture flasks (Corning) in DMEM/ F12 media (Gibco by Life Technologies), supplemented with EGF (10 ng/mL, PeproTech), FGF2 (10 ng/mL, PeproTech), N2 (5 $\mu \mathrm{l} / \mathrm{ml}$, Life Technologies) and B27 (1 ml/L, Life Technologies) and further differentiated for 40 days to functionally mature human neurons in 1:1 DMEM, neurobasal media containing B27 $(10 \mu \mathrm{l} / \mathrm{ml})$, Laminin $(1 \mu \mathrm{l} / \mathrm{ml})$ and $\mathrm{N} 2(5 \mu \mathrm{l} / \mathrm{ml})$ as previously described [20].

Neuronal differentiation of the human neuroblastoma cell line SH-SY5Y was performed as previously described [1]. In brief, SH-SY5Y cells were cultured and pre-differentiated for 7 days using $10 \mu \mathrm{M}$ retinoic acid (RA; Sigma-Aldrich; denoted as raSH-SY5Y). Pre-differentiated raSH-SY5Y cells were seeded on 6-, 12- or 24-well glass plates coated with $20 \%$ extracellular matrix (ECM) gel (BD Bioscience) and further differentiated for 10 days with serum-free MEM (Gibco by Life Technologies) supplemented with brainderived neurotrophic factor (BDNF, $50 \mathrm{ng} / \mathrm{ml}$, PeproTech), neuregulin $\beta 1$ (NRG $\beta 1,10 \mathrm{ng} / \mathrm{ml}$, R\&D Systems), nerve growth factor (NGF, $10 \mathrm{ng} / \mathrm{ml}, \mathrm{R} \& \mathrm{D}$ Systems) and vitamin D3 (VitD3, 24 nM, Sigma-Aldrich). These fully differentiated cells are denoted dSH-SY5Y.

In addition, SH-SY5Y cells expressing a CD63-EGFP fusion protein were generated using AddGene plasmid \#62964.

\section{Labelling and oligomerization of A $\beta$ 1-42}

Recombinant A $\beta 1-42$ peptides (Innovagen,) was dissolved in 1,1,1,3,3,3-hexafluoro-2-propanol (HFIP, Sigma-Aldrich) and vacuum dried overnight. A $\beta 1-42$ (1.054 mM final concentration) was resuspended in $\mathrm{Na}_{2} \mathrm{CO}_{3}(0.1 \mathrm{M} \mathrm{pH} 8.5)$ and incubated with the fluorophore Alexa Fluor 700 (AF700) succinimidyl ester $(1.58 \mathrm{mM}$ final concentration, Life Technologies) for $40 \mathrm{~min}$ at $4{ }^{\circ} \mathrm{C}$ or the fluorophore 6-carboxytetramethylrhodamine succinimidyl ester (TMR, Invitrogen), in a molar ratio of 2:, incubated overnight at $4{ }^{\circ} \mathrm{C}$. Labelled A $\beta 1-42$ was diluted to a final concentration of $100 \mu \mathrm{M}$ in HEPES $20 \mathrm{mM} \mathrm{pH} \mathrm{7.4,} \mathrm{vortexed,} \mathrm{sonicated} \mathrm{for} 10 \mathrm{~min}$ and incubated at $4{ }^{\circ} \mathrm{C}$ overnight. After the overnight incubation, A $\beta 1-42$ was separated from free dye with size exclusion chromatography (SEC). A Sephadex 75 10/300 GL column coupled to a liquid chromatography system (ÄKTA pure, GE Healthcare) was equilibrated with $\mathrm{NH}_{4} \mathrm{HCO}_{3} 50 \mathrm{mM}$ pH 8.5 and $500 \mu$ of sample was injected into the column. To estimate the molecular weight of the A $\beta$ species, LMW gel filtration calibration kits (GE Healthcare) were used. Oligomeric and monomeric $\mathrm{A} \beta$ species were eluted at a flow rate of $0.5 \mathrm{ml} / \mathrm{min}$, collected and lyophilized. Then, $\mathrm{A} \beta$ species (oA $\beta$-AF700) were resuspended in phosphatebuffered saline (PBS) solution and quantified spectrophotometrically at $215 \mathrm{~nm}$ by using the $\mathrm{A} \beta 1-42$ extinction coefficient (A $\beta 1-42 \varepsilon 214 \mathrm{~nm}=75,887 \mathrm{M}^{-1} \mathrm{~cm}^{-1}$ ) according to Lambert-Beer's law. Protein aliquots were stored at $-80^{\circ} \mathrm{C}$.

\section{Exosome purification, characterization and labelling}

Isolation of brain exosomes from extracellular space of freshly frozen human brain tissues $(250 \mathrm{mg})$ was performed as previously described [42]. Tissue was dissociated with papain (20 units/ml, $15 \mathrm{~min}$ at $37^{\circ} \mathrm{C}$, Sigma-Aldrich) followed by filtration through $40 \mu \mathrm{m}$ mesh filter (BD Biosciences) and a $0.2 \mu \mathrm{m}$ syringe filter (Thermo Scientific) to separate extracellular matrix from cells. The crude exosomes were then isolated by differential centrifugation method and subsequently purified by sucrose density gradient as previously described and resuspended in PBS, lysis buffer or diluent C (Sigma-Aldrich) for further experiments [42].

Exosomes from conditioned media of raSH-SY5Y cells were isolated by differential ultracentrifugation. In brief, 50-80 million raSH-SY5Y cells were incubated with oA $\beta$ AF700for $3 \mathrm{~h}$ at $37^{\circ} \mathrm{C}$. After PBS washing, cells were kept for $48 \mathrm{~h}$ in MEM supplemented with exosome-free serum (System Biosciences). Culture supernatants were collected and spun at $1000 \times \mathrm{g}$ for $10 \mathrm{~min}$ for removal of cellular debris. The supernatants were then filtered through $0.22 \mu \mathrm{M}$ filter and sequentially centrifuged at $5000 \times g, 10,000 \times g$, and $100,000 \times g$. The final pellet was then resuspended in PBS, lysis buffer or diluent $\mathrm{C}$ for further analysis.

Exosomes were labelled with PKH67 or PKH26 dye (Sigma-Aldrich), according to the manufacturer's protocol. Briefly, $4 \mu \mathrm{L}$ PKH67 dye was mixed with exosome suspension in diluent $\mathrm{C}$ and incubated for $10 \mathrm{~min}$ at $37{ }^{\circ} \mathrm{C}$. The labelling reaction was stopped by adding $20 \mathrm{ml}$ chilled PBS. Labelled exosomes were ultra-centrifuged at $100,000 \times g$ for $70 \mathrm{~min}$, washed with PBS, ultra-centrifuged again at $100,000 \times g$ and the pellet was resuspended in PBS. 


\section{Cellular uptake of exosomes}

dSH-SY5Y or hiPSCs cells were plated on coverslips in the respective serum-free growth medium. Before the uptake assay, exosomes were isolated from brain tissue or conditioned media of raSH-SY5Y cells and labelled with PKH67 or PKH26 as described above. In order to use equal amounts of exosomes in the cell cultures, exosomal protein content was quantitated by using BCA (Bio-Rad) or QuantIT (Invitrogen). Brain exosome abundance was quantified according to the AChE activity (EXOCET Exosome Quantification kit; System Biosciences) according to the manufacturer's protocol. The uptake was performed by incubating cell cultures with $100 \mu \mathrm{l}$ of exosome solutions (corresponding to an exosomal protein content of $0.62 \pm 0.28 \mu \mathrm{g} / \mu \mathrm{l}$ from brain or $0.71 \pm 0.33 \mu \mathrm{g} / \mu \mathrm{l}$ from conditioned media; equal to $1.4 \mathrm{e} 10$ exosome abundance from brain) in a humid chamber for $3 \mathrm{~h}$ $\left(37^{\circ} \mathrm{C}, 5 \% \mathrm{CO}_{2}\right)$. For inhibition experiments, cultured cells were pre-incubated for $30 \mathrm{~min}$ with the endocytosis inhibitors, dynasore (dynamin inhibitor, $80 \mu \mathrm{M}$ ), phenylarsine oxide (clathrin inhibitor $20 \mu \mathrm{M}$ ), genistein (caveolae inhibitor, $200 \mu \mathrm{M}$ ) all from Sigma-Aldrich. Isolated exosomes in PBS were added to cells for $3 \mathrm{~h}$ as above and flow cytometry was performed.

\section{Co-culture model}

Co-culture of donor-recipient cells was performed by using two different methods namely the coverslip system (where physical contact of synapses is possible) or the transwell system (where physical contact of synapses is not possible). In both cases, donor cells (raSH-SY5Y 12,500 cells $/ \mathrm{cm}^{2}$, or hiPSCs 25,000 cells $/ \mathrm{cm}^{2}$ ) were seeded on glass coverslips coated with $0.1 \mathrm{mg} / \mathrm{ml}$ poly-L-ornithine and $10 \mu \mathrm{g} / \mathrm{ml}$ laminin and cultured as described above for $3 \mathrm{~h}$ at $37{ }^{\circ} \mathrm{C}$ with either $1 \mu \mathrm{M}$ of oA $\beta$-AF700 or labelled exosomes from brain tissue or conditioned media, and thereafter washed twice with PBS.

In the transwell system, donor cells were seeded on a polycarbonate membrane filter with a $0.4 \mu \mathrm{m}$ pore size (Falcon, Corning), placed on top of recipient cells (dSH-SY5Y) and subsequently co-cultured for $24 \mathrm{~h}$. At the end of incubation, the membrane filter was removed and recipient cells were washed with PBS and analysed with flow cytometry or fixed with 4\% PFA for immunofluorescent labelling.

In the coverslip system, the donor cells were seeded on glass coverslips (VWR International) and placed upside down on top of recipient cells, predifferentiated as described above (resulting in donor cells facing recipient cells) and subsequently co-cultured for 24 or $48 \mathrm{~h}$ at $37{ }^{\circ} \mathrm{C}$. For gel cultured cells this results in a $3 \mathrm{D}$ environment. Thereafter, the coverslips with donor cells were removed and recipient cells were washed with PBS and either analysed with flow cytometry or fixed with 4\% PFA for immunofluorescent staining. Additionally, to control for donor cell contamination in the recipient cell samples, donor cells were transfected with BacMam 2.0 early endosomes Rab5a-RFP (Life Technologies) at a final concentration of 30 particles per cell before co-culture and RFP fluorescence was monitored in recipient cells by flow cytometry.

\section{Immunocytochemistry}

Co-localization of oA $\beta$ and flotillin-1 and TSG101 were visualized with immunostaining using 1: 5000 solution of mouse anti-mAb158, 1: 200 solution of mouse anti-flotillin-1 and a 1: 200 solution of mouse anti-TSG101. The secondary antibodies were $\mathrm{Cy} 3$ conjugated (Jackson Immuno Research, 1:1000) and Alexa Fluor 488-conjugated (Invitrogen, 1:400) goat anti-mouse IgG. GFP was detected using 1:200 rabbit anti-GFP (Life Technologies) and 1:400 goat anti rabbit Alexa flour 647 (Life Technologies).

\section{Cell microscopy}

Images of fixed cells were acquired with a Zeiss LSM 700 confocal microscope. The differential interface contrast (DIC) mode and 405, 488, 555 and 639 lasers were used to acquire the images with $63 \mathrm{x} / 1.40$ oil immersion planapochromatic DICII objectives. Live cell imaging were done using a Zeiss Primo Vert microscope. The micrographs were processed using Huygens (Scientific Volume Imaging) and ZEN lite (blue edition) software.

\section{Flow cytometry}

To detect PKH67 labelled exosomes or oA $\beta$-AF700, cells were released from the ECM gel using Corning Recovery Solution (Corning) according to manufacturer's instructions, filtered through CellTrics $30 \mu \mathrm{m}$ filters (Sysmex), re-suspended in PBS, and subsequently analysed on a BD FACSAria ${ }^{\mathrm{TM}}$ (BD Biosciences) flow cytometer.

After inhibiting the gene expression of exosome markers TSG101 and VPS4A in raSH-SY5Y cells, using RNA interference, the number of secreted exosomes were analysed using the Exo-Flow ${ }^{\mathrm{TM}}$ kit (System Biosciences, USA), targeting CD9, CD63 and CD81, as per manufacture's instruction.

\section{Enzyme-linked immunosorbent assay (ELISA) analysis}

Altogether, 96-well EIA/RIA plates (Corning Inc.) were coated at $4{ }^{\circ} \mathrm{C}$ overnight with $200 \mathrm{ng} /$ well of mAb158 in PBS. Plates were blocked with $1 \%$ bovine serum albumin (BSA) in TBS. Exosome samples prepared in RIPA buffer 
(150 mM sodium chloride, $1 \%$ Triton $\mathrm{X}-100,0.5 \%$ sodium deoxycholate, $0.1 \%$ sodium dodecyl sulfate and $50 \mathrm{mM}$ Tris, $\mathrm{pH}$ 8.0) were added to the plates in duplicates and incubated for $2 \mathrm{~h}$ at $37^{\circ} \mathrm{C}$. A total of $1 \mathrm{mg} / \mathrm{mL}$ of biotinylated mAb158 was added and incubated for $1 \mathrm{~h}$ at $22{ }^{\circ} \mathrm{C}$, followed by $1 \mathrm{~h}$ at RT incubation of streptavidin-coupled poly-HRP (Mabtech). K-blue enhanced (ANL product, Sweden) was used as HRP substrate and plates were read in a spectrophotometer at $450 \mathrm{~nm}$, using Spectra MAX 190 and then analysed with SOFT Max Pro. Wells were washed three times in TBST between each step. The 82E1 sandwich ELISA was performed same as above using $0.25 \mu \mathrm{g} / \mathrm{ml}$ for capture and detection antibody [56]. The amount of oA $\beta$ within exosomes was quantified with respect to a standard curve created with serial dilution of synthetic $A \beta$ oligomers and expressed as picomolar/mg of protein.

\section{Immunoblot analysis}

Exosomes were prepared as described above. Brain lysates were prepared from homogenised brain tissue followed by addition of lysis buffer $(150 \mathrm{mM} \mathrm{NaCl}, 0.5 \%$ deoxycholate, $1 \%$ Triton $\mathrm{X}-100,50 \mathrm{mM}$ tris-HCL pH 7.5, $20 \mu \mathrm{l} /$ $\mathrm{ml}$ phosSTOP (Roche), $10 \mu \mathrm{l} / \mathrm{ml}$ Halt Protease inhibitor cocktail (Thermo Fisher Scientific)), clarified by centrifugation at 10,000 $\mathrm{x}$ g for $5 \mathrm{~min}$ and sonicated using an ultrasonic probe. Cell lysates were prepared from cells collected in lysis buffer followed by homogenisation and sonication. Samples were mixed with 4x Laemlli loading buffer and separated on a ClearPAGE SDS Gel $4-12 \%$ or $10 \%$ (C.B.S. Scientific), and transferred onto a nitrocellulose membrane (Invitrogen). The gel was subsequently stained using InstantBlue protein stain (Expedeon). Additionally, exosomes, isolated from Control and AD brains or conditioned media of oA $\beta$-AF700-treated raH-SY5Y cells were lysed by freeze-thawing and subsequently run by SEC using the conditions described above. The eluted proteins were collected in fractions of $1 \mathrm{ml}$, lyophilized, resuspended in $15 \mu \mathrm{PBS}$ and spotted on $0.2 \mu \mathrm{m}$ nitrocellulose membrane. Membranes were then blocked by $3 \%$ BSA followed by primary antibody incubation. The following antibodies were used: anti-flotillin-1 (1: 500, BD Transduction Laboratories); anti-alix (1: 1000, EMD Millipore); anti-TSG101 (1:1000, Thermo Fisher Scientific); 1:1000, anti-VPS4A (Abcam), anti-calnexin (1:1000, Abcam), anti-synaptophysin (1:1000, Synaptic Systems), mAb158 (1: 5000/10000, BioArctic) and anti-glyceraldehyde 3-phosphate dehydrogenase (GAPDH, 1:40000, Synaptic Systems,). Anti-rabbit IgG, horseradish peroxidase (HRP)-linked antibody (1:3000, Dako) and antimouse IgG, HRP-linked antibody (1:3000, Dako) were used as secondary antibodies. The blots were visualized using Amersham $^{\text {TM }}$ ECL $^{\text {TM }}$ (GE Health Care) or SuperSignal ${ }^{\circledR}$
(Thermo Scientific) detection systems and analysed by ImageJ software.

\section{Negative staining and transmission electron microscopy of exosomes}

Exosome suspensions were fixed in $4 \%$ paraformaldehyde (at 1:1 dilution, for a final paraformaldehyde concentration of $2 \%$ ) overnight at $4{ }^{\circ} \mathrm{C}$ and stored at $-20{ }^{\circ} \mathrm{C}$ until use. Thawed exosome suspensions were vortexed briefly and centrifuged in a microcentrifuge for $30 \mathrm{~s}$. Exosomes were adsorbed on Formvar-coated Ni mesh grids by placing the grids on $5 \mu$ drops of exosome suspension for $20 \mathrm{~min}$ in a dry chamber. Negative staining was performed by gently dripping $100 \mu \mathrm{l} 2 \%$ aqueous uranyl acetate onto the grid, followed by removal of excess uranyl acetate solution using a lens paper. The grids were examined in a JEOL JEM-1230 electron microscope at $100 \mathrm{kV}$ accelerating voltage. Electron micrographs were obtained at 150,000-200,000× magnification, for a final image scale of 3.1-4.2 pixels/nm.

\section{Tunable resistive pulse sensing by qNano}

Exosome size and particle number were analysed by TRPS analysis using a qNano instrument (IZON Science, UK) as described previously [37]. First, isolated exosomes from brain tissue or conditioned media of dSH-SY5Y cells were diluted and passed through a $0.2 \mu \mathrm{m}$ filter (Millipore). Subsequently, particle numbers were counted for a maximum of 5 min or until 500 particles had been counted, using 8 mbar pressure and the NP150 or NP100 nanopore membranes with a stretch between 45 and $47 \mathrm{~mm}$. Voltage was set to 0.1 and $0.25 \mathrm{mV}$ to achieve a stable current. Particle size histograms were recorded when root mean square noise was below 13 $\mathrm{pA}$ and particle rate in time was linear. Calibration was performed using known concentration of beads CPC70D (mode diameter $70 \mathrm{~nm}$ ) or CPC100B (mode diameter: $110 \mathrm{~nm}$ ) (all from IZON) diluted in 1:500 0.2 $\mu \mathrm{m}$ filtered PBS.

\section{Proteinase K digestion}

To examine whether exosome-associated $A \beta$ is luminal or bound to the exterior exosome surface, exosomes were isolated from conditioned media (oA $\beta$ AF700-treated) of dSH-SY5Y cells and incubated with proteinase K (SigmaAldrich, $1 \mathrm{mg} / \mathrm{ml}$ ) for $30 \mathrm{~min}$ at $37{ }^{\circ} \mathrm{C}$. 4-(2-aminoethyl)benzene-sulfonyl fluoride (Sigma-Aldrich, $0.5 \mathrm{mM}$ ) was subsequently added to the vesicle fraction to inactivate the enzyme prior to two rounds of $100,000 \times$ g centrifugation. The final pellet was resuspended in PBS and AF700 fluorescence was measured in Tecan Safire2 microplate reader at Ex/Em 696/719 nm. 


\section{Cytotoxicity assay}

To investigate the toxic effect of exosomes on neurons, equal amounts of exosomes (based on exosomal protein estimation by BCA) from brains or cells were added to dSH-SY5Y cells and hiPSCs in our co-culture model for $48 \mathrm{~h}$, as described above. At the end of incubation, donor cells were removed and cell medium was collected to assess the release of lactate dehydrogenase (LDH) in the medium. Collected medium was centrifuged $2000 \times g$ for $5 \mathrm{~min}$ at $4{ }^{\circ} \mathrm{C}$ and LDH assay (Pierce) was performed according to manufacturer's instructions. The absorbance was measured in a microplate reader (SpectraMAX 190) at $490 \mathrm{~nm}$ with subsequent blank at $680 \mathrm{~nm}$. Furthermore, XTT (2,3-bis [2-methoxy-4-nitro-5sulfophenyl]-5-[(phenylamino) carbonyl]-2H-tetrazolium hydroxide) assay using the Cell Proliferation Kit II (Roche Diagnostics $\mathrm{GmbH}$ ) was performed on acceptor cells according to the manufacturer's instructions. The reduced XTT product produced by mitochondrial enzymes in viable cells, formazan (bright orange in colour) was measured after $8 \mathrm{~h}$ of incubation at 450 and $750 \mathrm{~nm}$ using a Victor $3 \mathrm{~V} 1420$ multilabel plate reader (PerkinElmer). Both LDH and XTT values were presented as percentage of untreated control.

\section{RNA interference}

Cells were seeded at a density of 12500 cells $/ \mathrm{cm}^{2}$ in a 6-well plate and transfected $24 \mathrm{~h}$ later with TSG101 or VPS4 mRNA-targeting siRNA or a non-targeting siRNA with no homology to any known human gene (All Stars Negative Control siRNA) with the HiPerFect transfection reagent (all from Qiagen) according to manufacturer's protocol. TSG\#6 (CAGTTTATCATTCAAGTGTAA), TSG\#3 (ACTGTCAAT GTTATTACTCTA), VPS\#7 (AAGCTGAAGGATTATTTA CGA) and VPS\#5 (CTCAAAGACCGAGTGACATAA) siRNAs were used for this study. The final siRNA concentrations in the culture medium ranged from 10 to $20 \mathrm{nmol} / \mathrm{l}$. Twenty-four hours after transfection, knockdown was verified by quantitative real-time PCR and Western Blot analyses, and a decrease in the mRNA level of $70 \%$ or greater was considered sufficient downregulation.

\section{Gene expression analysis}

Total RNA was extracted with the RNeasy Mini Kit (Qiagen), and cDNA was obtained with the High Capacity RNA-to-cDNA Kit (Applied Biosystems). The expression levels of TSG101 or VPS4 mRNA were analysed with a 7500 Fast Real-Time PCR system and FAM/MGB probes (Applied Biosystems) to confirm downregulation after siRNA treatment. All reactions were performed according to the manufacturer's instructions. GAPDH was amplified as an internal standard. The data were calculated according to the comparative $\mathrm{Ct}$ method to present the data as fold differences in the expression levels relative to the control sample.

\section{Statistics}

All statistical analyses were performed using GraphPad Prism Software. Data were expressed as the mean \pm SEM, and statistical comparisons were made using two-tailed unpaired Student's $t$ tests with Welch's correction or oneway ANOVA with Tukey's correction. Every batch of cell cultures was treated as one independent experiment $(n=1)$. $P$ values less than or equal to 0.05 were deemed statistically significant.

\section{Study approval}

The collection and use of post mortem brain tissue was approved by the Regional Ethical Committee in Uppsala, Sweden (2005/103, 2005-06-29; 2009/089; 2009-04-22). The process of reprogramming human cells was approved by the Ethical Committee at Karolinska Institute, Sweden (dnr 2012/208-31/3 with addendum 2012/856-32). A written informed consent was received from all donors.

\section{Results}

\section{Alzheimer brain exosomes are enriched with oA $\beta$}

To examine whether oA $\beta$ has the potential to localize to cellular structures that form exosomes in the AD brain we analysed the co-localization of potential oA $\beta$ labelling and the marker flotillin-1, expressed in multi-vesicular bodies and exosomes. Brain sections from temporal neocortex from four post mortem $\mathrm{AD}$ brains were double-immunostained with flotillin- 1 and one of two different $A \beta$ antibodies (mAb158 or 82E1). Cells with neuronal morphology displayed both mAb158 or 82E1 and flotillin-1 labelling (Fig. 1a, b). Next, the possible co-localization of $\mathrm{mAb} 158$ or $82 \mathrm{E} 1$ with flotillin-1 was analysed on immunofluorescently labelled, fixed brain sections using the same antibodies. Although the resolution is not sufficient to prove co-localization, we observed a strong correlation between mAb158 or 82E1 and flotillin-1 labelling, suggesting a subcellular co-localization (Fig. 1c, d) $\left(R^{2}=0.78\right.$ and 0.86 for $\mathrm{mAb} 158$ and $82 \mathrm{E} 1$, respectively $)$. The detected fluorescence was not due to lipofuscin-derived autofluorescence (Supplementary Fig. S1a). Currently, no antibodies with verified $\mathrm{oA} \beta$ selectivity in IHC applications have been reported. Thus, we selected the two $A \beta$ antibodies with most extensive data on oligomer selectivity in other 

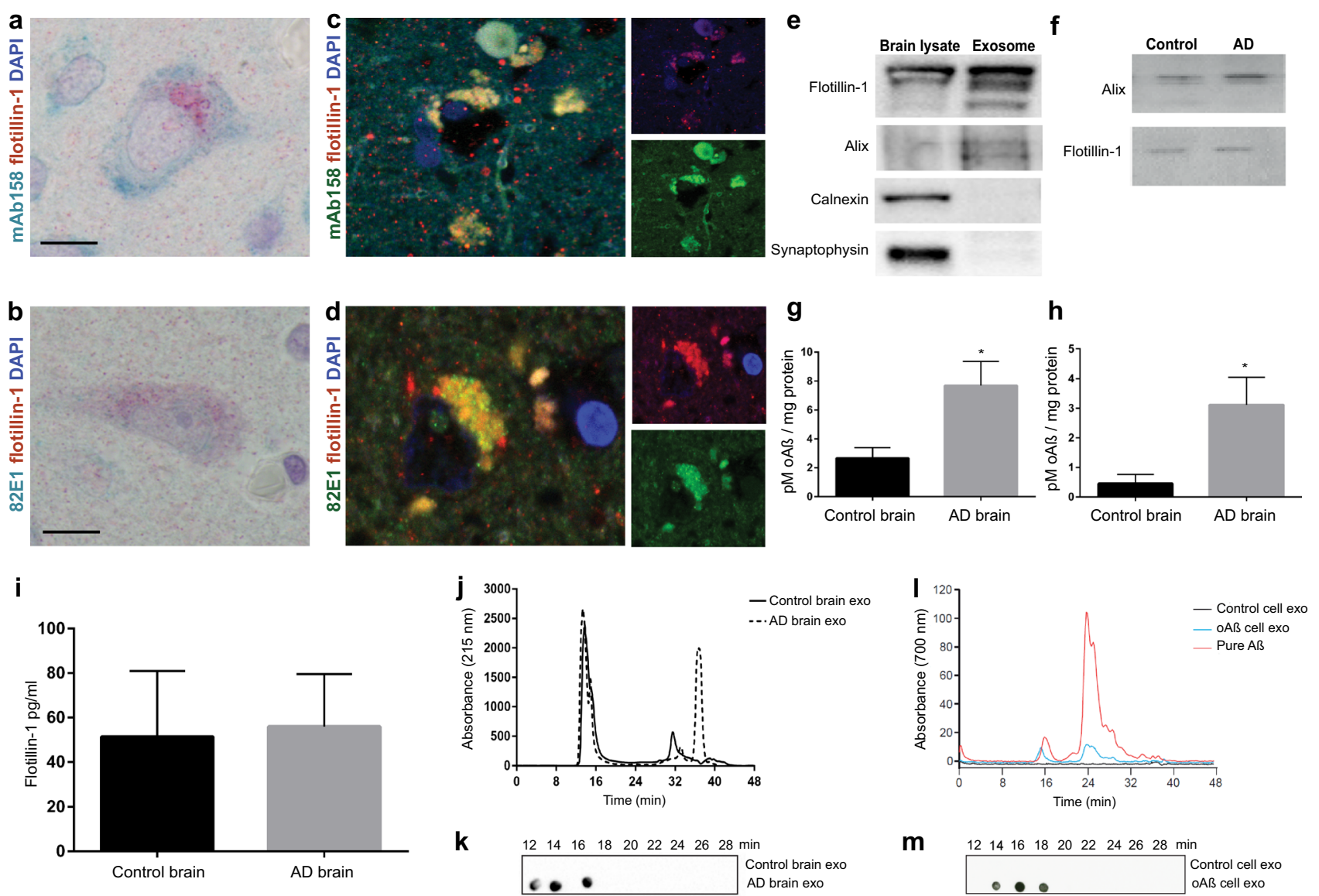

m

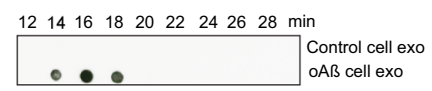

Fig. 1 AD brain exosomes are enriched with $\mathrm{oA} \beta$. AD brain sections from temporal neocortex show co-localization of probable oA $\beta$ to exosomes. a, b Double-immunostaining with the exosome marker flotillin-1 (labelled red), and two different oligomer-selective (see main text) $\mathrm{A} \beta$ antibodies $\mathrm{mAb} 158$ and $82 \mathrm{E} 1$, respectively (labelled bluegreen). Scale bar $10 \mu \mathrm{m}$. c, $\mathbf{d}$ Co-localization of oA $\beta$ to exosomes was performed after immunofluorescence labelling. mAb158 or 82E1, respectively, showed substantial co-localization (yellow) with flotillin- 1 inside cells in the $\mathrm{AD}$ brain $\left(R^{2}=0.78\right.$ and 0.86 for mAb158 and 82E1, respectively). Scale bar, $5 \mu \mathrm{m}$. e Immunoblot showing flotillin-1, alix, calnexin and synaptophysin in exosome and brain lysate, demonstrating no cellular or synapse vesicle contamination in the exosome preparation. Loading control is shown in Supplementary Fig. S1d. f Immunoblot demonstrating the presence of flotillin-1 and alix, in exosome fractions isolated from control and AD brain. Quantitative ELISA analysis of $\mathrm{oA} \beta$ in exosomes isolated from $\mathrm{AD}$ and control brains, using 82E1 (h) and mAb158 (g) antibodies, respec-

assays (mainly ELISA). Both these antibodies showed similar labelling patterns in brain tissue (Fig. 1a-d). Furthermore, our findings from dot-blot (Fig. 1k, m, described below) supports that mAb158 has a selectivity for aggregates over monomers also in assays where the protein is in a bound state. Taken together, these data indicate that the identified $A \beta$ labelling likely represents oligomeric $A \beta$ aggregates. Thus, our findings suggest an association of oA $\beta$ with intracellular compartments containing flotillin-1, tively. Data are presented as the mean picomolar of oA $\beta$ per mg total exosome protein \pm SEM $(n=3)$. ${ }^{*} p<0.05$ by two-tailed unpaired Student's $t$ tests with Welch's correction. i Quantitative analysis of flotillin- 1 by ELISA in control and AD brain exosomes showing equal amount of flotillin-1 between the groups. $\mathbf{j}$ Representative SEC profile of lysed exosomes isolated from control and $\mathrm{AD}$ brain samples at $215 \mathrm{~nm}$ absorbance (general protein detection). $\mathbf{k}$ Detection of $\mathrm{oA} \beta$ in SEC eluate fractions of AD and control brain exosomes by dot blot using mAb158 antibody. I SEC chromatograms of exosomes isolated from conditioned media of control- or oA $\beta$-AF700 treated dSH-SY5Y cells as well as pure oA $\beta$-AF700. Detection at $700 \mathrm{~nm}$ absorbance (AF700 detection). m Dot blot detection of oA $\beta$ (mAb158 antibody) in SEC eluate fractions of exosomes isolated from conditioned media of control- or oA $\beta$-AF700 treated dSH-SY5Y cells of control and oA $\beta$-AF700 treated dSH-SY5Y cells exosomes. The analysis of SEC fractions confirms the presence of oA $\beta$ in exosomes

including multivesicular bodies, in the human AD brain, which thus suggests that $O A B$ could be released in exosomes.

Since oA $\beta$ is believed to be central to AD pathophysiology [50], we postulated that exosomes from AD brains would contain higher concentrations of oA $\beta$ when compared to similar preparations of control brain samples from patients deceased from non-neurological reasons. Using well-established methods for mild dissociation of nervous tissue followed by separation of extracellular matrix from cells we were able to isolate exosomes by sequential 
a

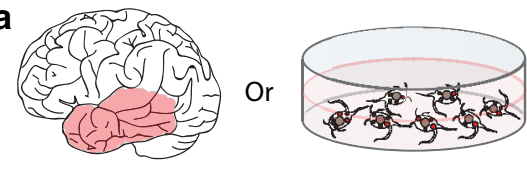

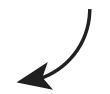

1. Isolation and fluorescent labeling of exosomes containing $O A \beta$ from $A D$ brain or cells in culture

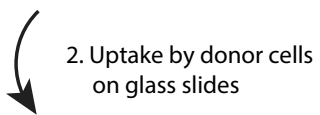
को सर figure b-c at $y$ figure $\mathrm{f}-\mathrm{g}$

3. Co-culture slides upside down on top of acceptor cells
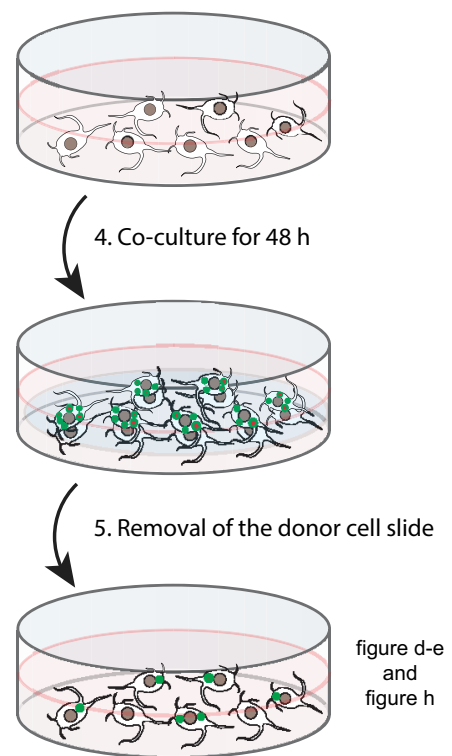

6. Quantification of transfer with

confocal microscopy and cytotoxicity assays

Exosomes PKH67

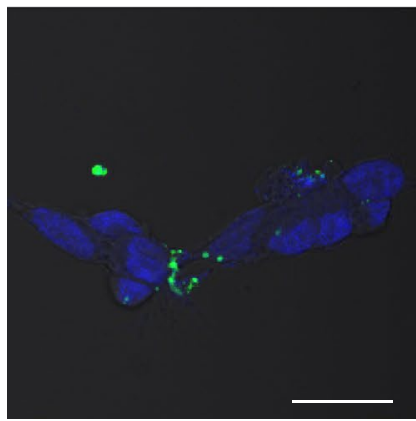

Exosomes oAß
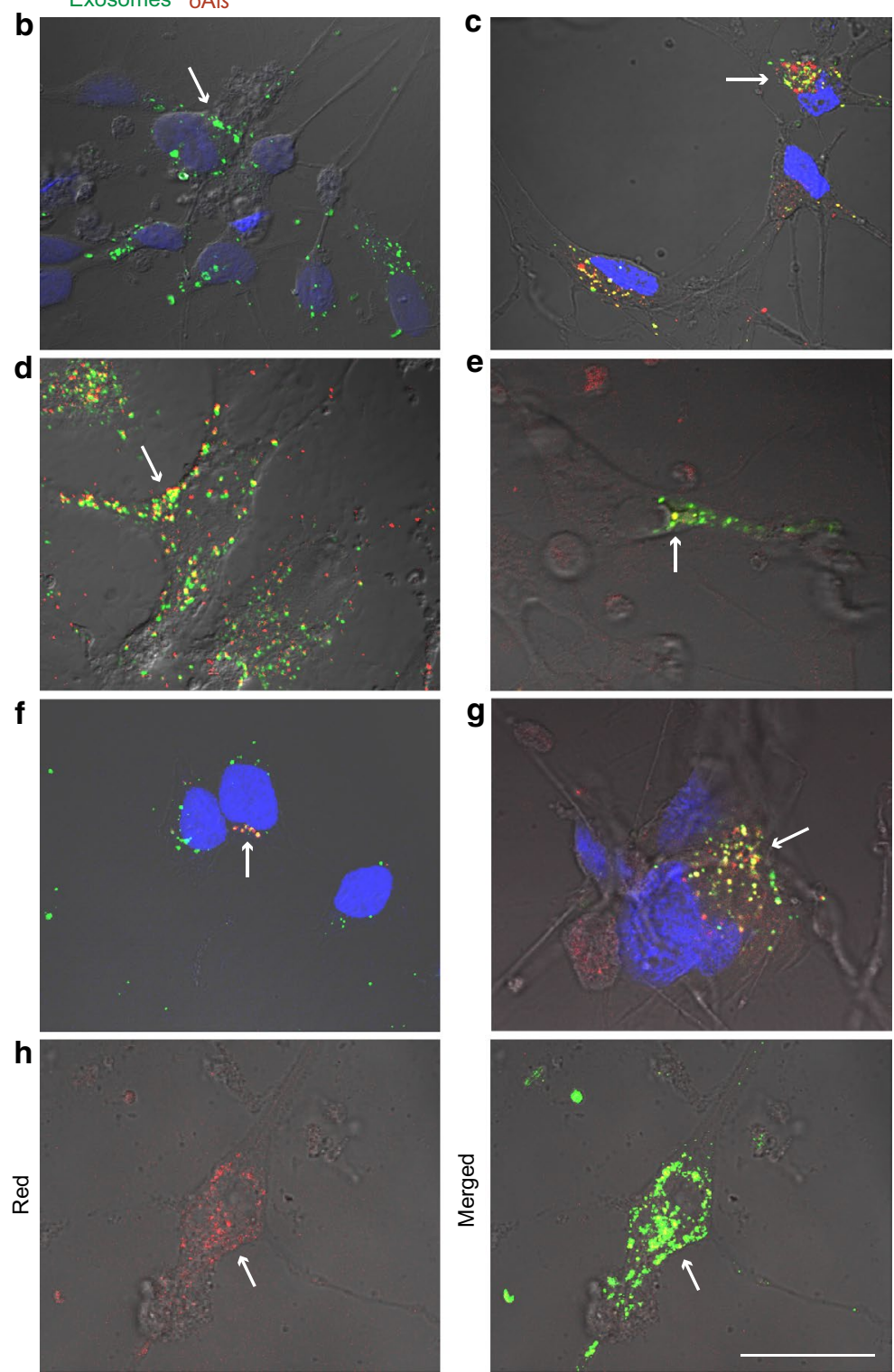

e

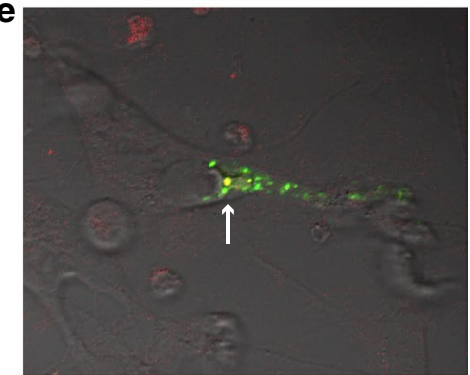

g
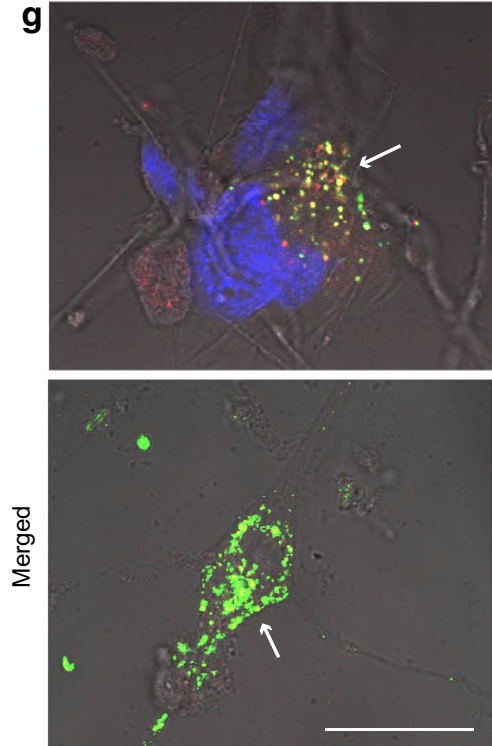

Exosome free fraction $\mathrm{PKH} 67$

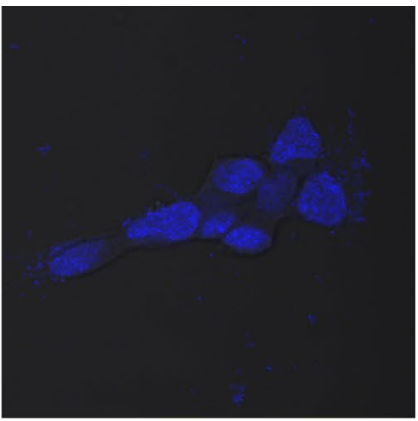

CD63 GFP expressing exosomes

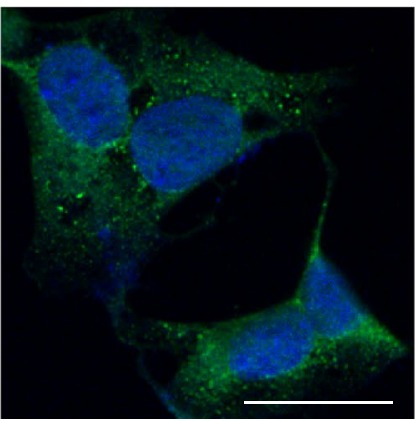

Exosomes PKH26

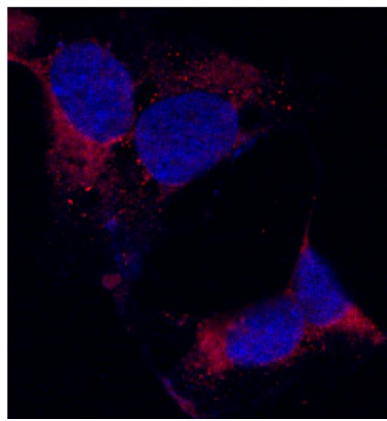


४Fig. 2 Exosome-mediated uptake and propagation of oA $\beta$ in neuronal cells. Exosomes isolated from brain tissue or conditioned media of dSH-SY5Y cells were labelled with the dye PKH67 and added to donor hiPSCs or dSH-SY5Y cells. After $3 \mathrm{~h}$ of incubation at $37{ }^{\circ} \mathrm{C}$, donor cells were fixed, stained with mAb158 (for brain exosomes) and analysed by confocal microscopy or donor cells were co-cultured with another set of hiPSCs or dSH-SY5Y (recipient cells). After $48 \mathrm{~h}$ of co-culture, donor cells were removed and recipient cells were fixed, stained with mAb158 (for brain exosomes) and analysed by confocal microscopy. a A cartoon illustrating the coculture model with hiPSC or dSH-SY5Y cells employed to measure the transfer of the brain or cell exosomes containing oA $\beta$. Uptake of b control and c $\mathrm{AD}$ brain exosomes (green) containing $\mathrm{oA} \beta$ (red) in hiPSC donor cells. Transfer of AD brain exosomes (green) containing oA $\beta$ (red) to recipient $\mathbf{d}$ hiPSCs and e dSH-SY5Y cells. Uptake of exosomes (green) containing oA $\beta-\mathrm{AF} 700$ (red) in donor $\mathbf{f} \mathrm{dSH}$ SY5Y and $\mathbf{g}$ hiPSCs. $\mathbf{h}$ Transfer of oA $\beta$-AF700 containing exosomes in recipient dSH-SY5Y cells. Super-imposed image of the red (oA $\beta$ ) and green (exosomes) channels on a DIC image shows co-localization (yellow) of exosomes and oA $\beta$. Arrows indicate exosomes or exosome containing oA $\beta$. i Cellular uptake of isolated brain exosomes and brain exosome free fraction after PKH67 staining showing no PKH67 uptake in the absence of exosomes. $\mathbf{j}$ Isolated exosomes from CD63-GFP expressing SH-SY5Y cells, double-labelled with PKH26 (red), were added to dSH-SY5Y cells. The CD63-GFP were intensified using an anti-GFP antibody. Scale bar $(\mathbf{b}-\mathbf{h}), \mathbf{j} 20 \mu \mathrm{m}, \mathbf{i} 10 \mu \mathrm{m}$

ultracentrifugation from fresh-frozen, post mortem brain tissues from temporal neocortex of both AD and control subjects. Analyses of the isolated fractions by Tunable Resistive Pulse Sensing technology (TRPS, qNano system) and transmission electron microscopy (TEM, Supplementary Fig. S1b, c) demonstrated presence of vesicles with a size corresponding to exosomes [55]. Immunoblotting confirmed the extracellular origin of the extracted vesicles by presence of the exosomal markers alix and flotillin-1 and the lack of the cellular marker calnexin and the synapse vesicle marker synaptophysin (Fig. 1e). Furthermore, immunoblotting confirms the presence of exosomal markers in extracted vesicles from both control and AD brains (Fig. 1f). As immunostaining of flotillin- 1 and $\mathrm{oA} \beta$ in the AD brain sections does not have the sufficient resolution, ELISA, which is a more quantitative method, was implemented to demonstrate the oA $\beta$ in brain exosomes. When used as capture and target in an ELISA the A $\beta$ antibodies mAb158 is selective for A $\beta$ oligomers $[19,57]$, while $82 \mathrm{E} 1$ detects both soluble and fibril $A \beta$ [31]. Interestingly, ELISA with either one of these two oligomer-selective antibodies showed significantly higher levels of oAß in exosomes from $\mathrm{AD}$ brains $(n=5$, $3.12 \pm 0.93 \mathrm{pM} \mathrm{oA} \beta / \mathrm{mg}$ protein for $82 \mathrm{E} 1$ and $7.69 \pm 1.68 \mathrm{pM}$ $\mathrm{oA} / \mathrm{mg}$ protein for $\mathrm{mAb} 158$ ) than in those from healthy control brains $(n=5,0.46 \pm 0.30 \mathrm{pM} \mathrm{oA} \beta / \mathrm{mg}$ protein for $82 \mathrm{E} 1$ and $2.66 \pm 0.74 \mathrm{pM} \mathrm{oA} / \mathrm{mg}$ protein for $\mathrm{mAb} 158$ ) (Fig. 1g, h). There was no significant difference in the amount of flotillin-1 in exosomes derived from AD or control brain tissue of equivalent weight (Fig. 1i). The increase in exosomal oA 3 was not an effect of co-precipitation of free $\mathrm{o} A B$ during the extraction as spiking exosomes with exogenous $\mathrm{OA} \beta$ did not result in increased levels, which also implies that association of oAß with exosomes occurs intracellularly (Supplementary Fig. S1e). Additionally, the presence of oA $\beta$ in isolated exosomes was further assessed using size exclusion chromatography (SEC). SEC chromatograms of the isolated and lysed exosomes from control and AD brain samples were analysed at $215 \mathrm{~nm}$ absorbance (general protein detection) and proteins were detected in the void volume (first peak) as well as in fractions corresponding to lower molecular weight (Fig. 1j). The presence of $\mathrm{oA} \beta$ in the different SEC eluate fractions was further investigated by dot-blot analysis using mAb158. This confirmed that exosomes isolated from AD brain samples contained $\mathrm{oA} \beta$ in SEC fractions running at the oligomer size that was not detected in control brain (Fig. 1k). Similarly, lysed exosomes isolated from conditioned media of control- or oA $\beta$-AF700 treated neuronally differentiated neuroblastoma cells (dSH-SY5Y) as well as pure oA $\beta$-AF700 were analysed on SEC chromatograms with detection at $700 \mathrm{~nm}$ absorbance (AF700 detection). This shows absorbance peaks (oligomeric and monomeric) at the same time points (size) for exosomes from conditioned media of oA $\beta$-AF700 treated cells as for the pure oA $\beta$-AF700 initially used to treat the cells (Fig. 11). oA $\beta$ was detected only in fractions from exosomes from conditioned media of oA $\beta$-AF700 treated dSH-SY5Y cells and not in control cell exosomes (Fig. 1m). Furthermore, these findings show that, in addition to previously shown $\mathrm{A} \beta$ oligomer selectivity in ELISA assay [19, 57], the mAb158 antibody is oligomer selective also in an assay where protein is not free floating.

The localization of $\mathrm{OA} ß$ to exosomes was further investigated in neuronal cell models. dSH-SY5Y or hiPSC were incubated with oA $\beta$-AF700 for $3 \mathrm{~h}$, after $48 \mathrm{~h}$ exosomes were isolated from the conditioned media by sequential ultracentrifugation. Similar to the brain extractions, the isolated vesicles were characterized as exosomes using immunoblotting for the exosome markers, alix and flotillin-1, lack of cellular marker calnexin and synapse vesicle marker synaptophysin, TRPS and TEM (Supplementary Fig. S2a-d) [35, 54]. To investigate the location of $\mathrm{oA} \beta$, exosomes isolated from conditioned media from oAß-AF700 treated retinoic acid differentiated SH-SY5Y cells (raSH-SY5Y) were treated with proteinase $\mathrm{K}(1 \mathrm{mg} / \mathrm{ml})$ to digest proteins on the surface, confirming that the localization of oA $\beta$ is mainly luminal as this did not significantly decrease exosomal oA $\beta$ AF700 (Supplementary Fig. S2e).

\section{Exosomes from AD brain are internalized and transferred by neurons, causing cytotoxicity}

To investigate whether exosomes could be a vehicle for the spreading of oAß, we investigated if exosomes isolated from 
AD brains could be taken up by hiPSCs and dSH-SY5Y cells (Fig. 2a). The cells were incubated with exosomes (PKH67 labelled) isolated from brain tissue. After $3 \mathrm{~h}$, both exosomes (Fig. 2b) and oAß (mAb158, Fig. 2c) had been taken up by the cells. Using a co-culture system with hiPSCs or dSHSY5Y cells, previously shown to result in synaptically connected neurons [40], we next investigated the possible transfer of brain-derived exosomal oA $\beta$ between these neurons. When RFP labelled donor cells that had been exposed to exosomes were placed on top of recipient neurons for $48 \mathrm{~h}$, a substantial number of transferred exosomes (PKH67) and oA $\beta$ (mAb158) could be detected in both types of recipient cells (Fig. 2d, e). Moreover, transferred oAß was still partly co-localized with PKH67 labelled exosomes in the recipient cells, suggesting that after being internalized part of the exosomes can be transferred onwards, still intact with their oAß content. Similarly, uptake of oAß in raSH-SY5Y treated with oA $\beta$-AF700 $(3 \mathrm{~h})$ resulted in a co-localization with intracellular flotillin-1 and TSG101 (Supplementary Fig. S3a-b). Isolated ( $48 \mathrm{~h}$ conditioned media) and labelled (PKH67) exosomes were readily taken up by new cells. A high degree of internalization of exosomes in either dSHSY5Y (Fig. 2f) or hiPSC (Fig. 2g) cells was observed. These vesicular structures had a mainly perinuclear localization and many of them were positive for oA $\beta$-AF700. Using these secondary neurons as donor cells and co-culturing them with a new set of dSH-SY5Y recipient cells for $24 \mathrm{~h}$ showed further spread of AF700 labelled oA $\beta$ to this third set of cells (red channel, Fig. 2h). Similarly to what we observed for exosomes from AD brains, we could detect a substantial fraction of oA $\beta$ that was still co-localized with exosomes (merged, Fig. 2h). These findings support that, apart from releasing their cargo, intact exosomes also can carry and transfer $o A \beta$ further to new recipient cells. Likewise, exosomes isolated from conditioned media from cells that had not been exposed to oA $\beta$ were also taken up by cells and transferred onwards (Supplementary Fig. S3c), corroborating that the release and uptake of exosomes per se is not dependent on the presence of oAß. To confirm that the observed PKH labelling is not due to artefacts we used the supernatant from the last ultracentrifugation wash-step of the exosome isolation from brain or conditioned media, respectively. The supernatant was labelled with PKH67 using the same protocol as for labelling the exosomes. The labelled sample were subsequently added to raSH-SY5Y cells. Contrary to the exosome fraction the exosome-free fraction did not result in any labelling in the cells either in brain (Fig. 2i) or conditioned media extracts (Supplementary Fig. S3d). Furthermore, isolated exosomes from CD63GFP expressing raSH-SY5Y cells were double-labelled with PKH26 (red) and added to raSH-SY5Y cells (Fig. 2j). This confirmed that the exosomes studied here are not artefacts, but indeed exosomes.
Further evidence for the exosomal transportation of oA $\beta$ was obtained by using a transwell co-culture model after uptake of oA $\beta$ containing exosomes to donor cells. Also, in this model oA $\beta$ transferred to recipient cells, suggesting vesicle transfer of oA $\beta$ between cells without direct neuritic connections. However, compared to the coverslip co-culture model significantly less neurons containing transfer of oA $\beta$ was detected in the transwell model, a decrease from 23.60 to $5.18 \%$ as analysed by flow cytometry and illustrated by confocal imaging (Supplementary Fig. S4a, b). Thus, suggesting that transfer is more efficient between cells in proximity, which could potentially depend on multiple mechanisms of transfer.

Next, we investigated if the spread of exosomes and their $\mathrm{oA} ß$ cargo could result in neuronal toxicity. Isolated brain exosomes (equalized by protein amounts) from either control or AD brains were added to dSH-SY5Y cells for $3 \mathrm{~h}$, these cells were used as donor cells in $48 \mathrm{~h}$ co-culture with recipient dSH-SY5Y cells. The recipient cells were subsequently investigated for morphological changes compared to control co-culture with untreated donor cells (Fig. 3a). As described previously [2] the control dSH-SY5Y shows neuronal morphology with long, branching networks of neurites. Similar morphology was seen in recipient cells in the control brain exosome conditions. Occasional changes in neurite morphology could be identified. Interestingly, more pronounced pathology was seen in recipient cells co-cultured with $\mathrm{AD}$ brain exosome treated donor cells. Here dystrophic neurites with neurite beading and loss of neurite branching were identified, known early signs of neurodegeneration [51]. We quantified these effects further and notably, we found that the transfer of AD brain exosomes induced significant cytotoxicity compared to control brain exosomes, as assessed by the degree of membrane leakage of lactate dehydrogenase enzyme (LDH) from the recipient hiPSC and dSH-SY5Y cells (Fig. 3b, c). Induced cellular toxicity was also detected by XTT (2,3-bis [2-methoxy-4-nitro-5-sulfophenyl]-5[(phenylamino) carbonyl]-2H-tetrazolium hydroxide) analysis in both cell types (Fig. 3d, e). Similar toxicity was further seen after treatment with exosomes from conditioned oA $\beta$ media (Fig. 5d). In addition, exosomes from control brains which should contain significantly less oAß, caused toxicity in hiPSCs but not in dSH-SY5Y cells (Fig. 3b, e). No toxicity was seen after treatment with exosomes from conditioned media from cells not treated with oA $\beta$ (Supplementary Fig. S5a). Taken together, these results suggest that intact $A D$ brain exosomes, carrying $\mathrm{oA} \beta$, are taken up by neurons and migrate to second order neurons where they can release their cargo and cause cytotoxicity. 

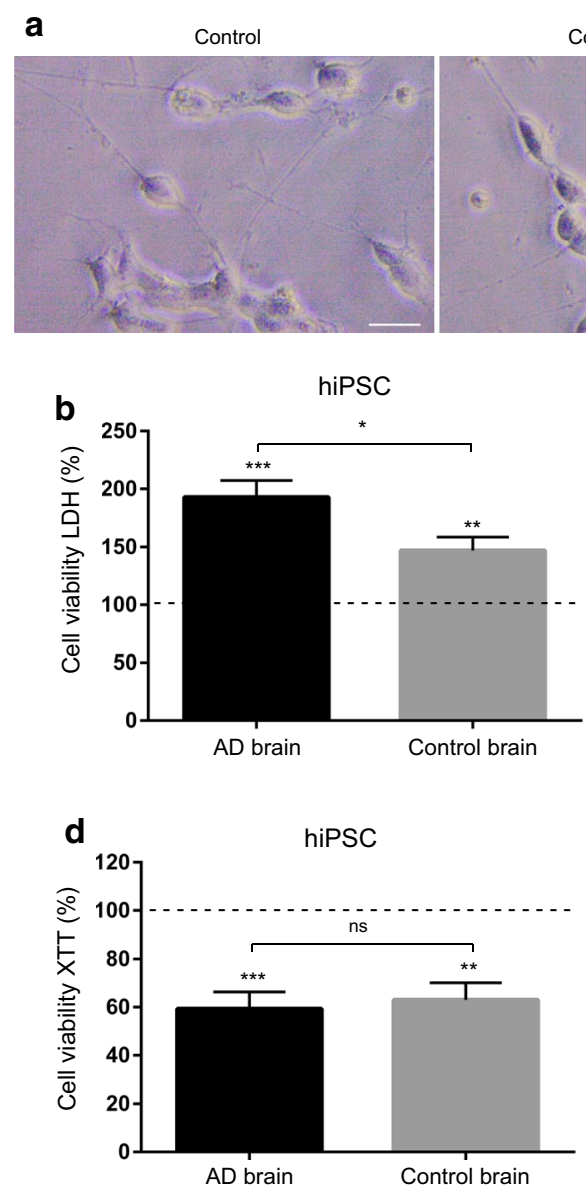

Fig. 3 Transfer of AD brain exosomes causes cytotoxicity. Exosomes isolated from control and $\mathrm{AD}$ brain tissues were added to donor hiPSCs or dSH-SY5Y cells. After $3 \mathrm{~h}$ of incubation at $37{ }^{\circ} \mathrm{C}$, donor cells were washed with PBS and co-cultured with another set of hiPSCs or dSH-SY5Y (recipient cells). After $48 \mathrm{~h}$ of co-culture, donor cells were removed. a Morphological changes assessed in recipient dSHSY5Y showing loss of neurite branching after transfer of $\mathrm{AD}$ brain exosomes. Also, neurite beading was seen in dystrophic neurites as

\section{Inhibition of exosome formation and secretion inhibit the spread of $O A \beta$}

If exosomes are capable of transferring oA $\beta$ between neurons, it should be possible to stop this transfer by inhibiting the formation of exosomes. As previously shown, biogenesis of exosomes and its cargo proteins can be modulated by knocking down two Endosomal Sorting Complexes Required for Transport (ESCRT) proteins, TSG101 and VPS4A, required for exosome formation and secretion, respectively [3, 18, 21, 30]. By using siRNA oligonucleotides, a significant decrease in the mRNA levels (decreased in average with $90 \%$ for TSG101 and $88 \%$ for VPS4A), protein levels (decreased in average with $87 \%$ for TSG101 and $65 \%$ for VPS4A) and the number of secreted exosomes (decreased in average with 95\% for TSG101 and 76\% for
Control brain exo

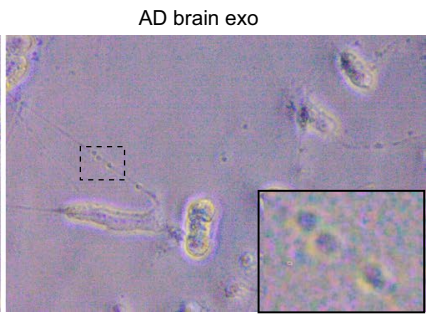

AD brain exo
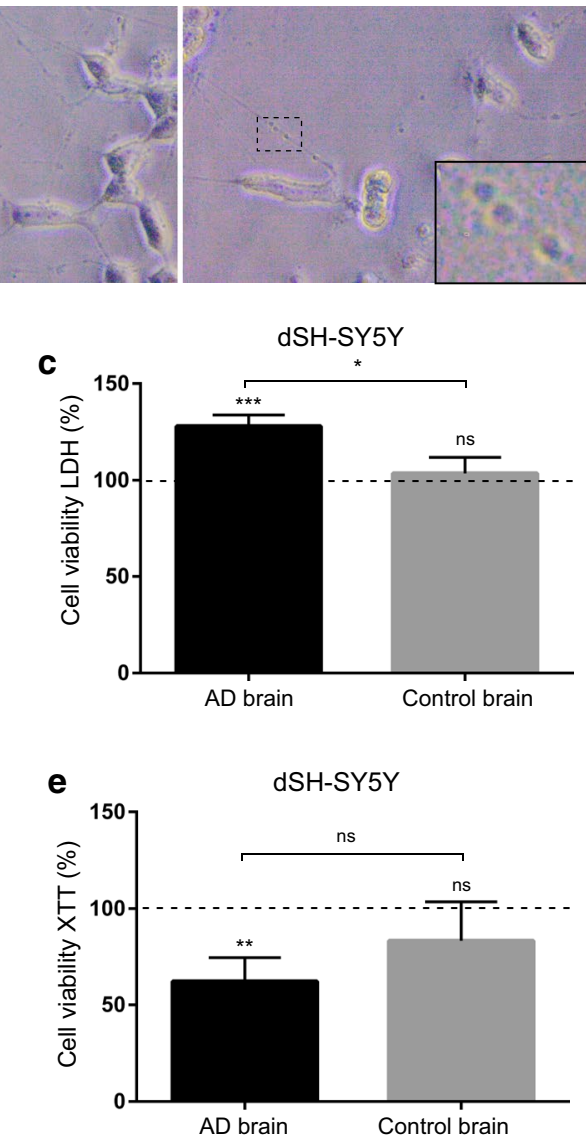

shown in magnified insert. The conditioned media was collected for LDH assay $(\mathbf{b}, \mathbf{c})$ and recipient cell viability evaluated by XTT $(\mathbf{d}, \mathbf{e})$. Values are expressed as percentage of untreated control. Values are mean \pm SEM ( $n=6$ separate experiments). LDH shows that transfer of $\mathrm{AD}$ brain exosomes causes significant higher cytotoxicity compared to control brain exosomes in both cell types. NS, not significant; $* p<0.05, * * p<0.01, * * * p<0.001$ by two-tailed unpaired Student's $t$ tests with Welch's correction

VPS4A) (Fig. 4a-c) was achieved. The siRNA treatment did not affect viability, as analyses showed that $>95 \%$ of the cells were viable as measured by XTT assay (Fig. 4d). To distinguish between different mechanisms of transfer, we again used the coverslip and transwell co-culture models and quantified the $o A \beta$ transfer in presence of TSG101 or VPS4A siRNA in our co-culture model using flow-cytometry. Interestingly, upon inhibition of exosome formation and secretion the oA $\beta$ transfer was almost completely blocked in the transwell model, whereas almost half of the oA $\beta$ transfer could be stopped in the coverslip model (Fig. 4e). These results indicate that exosomes are largely responsible for the neuron-to-neuron transfer of oA $\beta$, although other mechanisms of transfer may also be involved. 

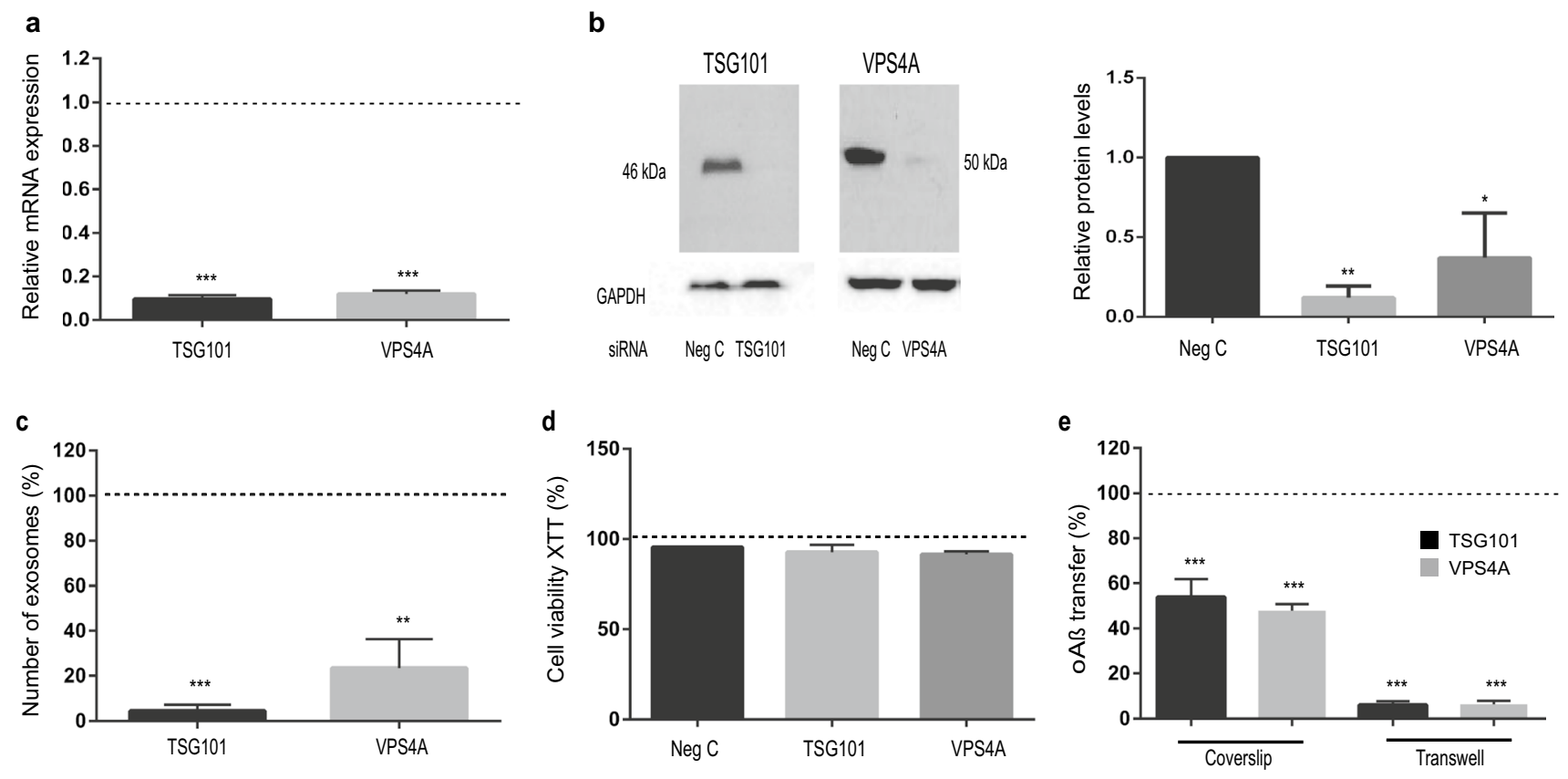

Fig. 4 Downregulation of exosomal proteins TSG101 and VPS4A inhibits the spread of oA $\beta$. Depletion of TSG101 and VPS4A by siRNA in dSH-SY5Y cells. a Real time PCR analysis of mRNA expressions to show knock down efficiency of transfected cells by TSG101 or VPS4A siRNA. b Representative immunoblot picture of cell lysates after siRNA treatment for $72 \mathrm{~h}$ and associated densitometric analysis $(n=3)$. $\mathbf{c}$ Bead flow cytometry analysis of exosomes shows a significant decrease in the number of secreted exosomes after TSG101 or VPS4A siRNA treatment in raSH-SY5Y cells. d No cyto-

\section{The uptake of exosomes and spread of oAß is dynamin-dependent and can be blocked}

After being released, the exosomes can be taken up by the recipient cells via different mechanisms. In dSH-SY5Y cells the uptake of isolated exosomes observed at $37^{\circ} \mathrm{C}$, as described above, was completely abrogated at $4{ }^{\circ} \mathrm{C}$ (Supplementary Fig. S5b). Thus, the exosomal uptake is an active process. Neuronal cells are capable of different modes of endocytosis, ranging from receptor-mediated and clathrindependent, to independent endocytosis [10, 34, 47]. To explore the uptake mechanism, we treated dSH-SY5Y cells with isolated, PKH67 labelled, exosomes together with various inhibitors of endocytosis: dynasore (dynamin inhibitor), phenylarsine oxide (clathrin inhibitor) and genistein (caveolae inhibitor). Treatment with phenylarsine oxide caused minor cellular toxicity, while no notable cellular toxicity was observed upon treatment with dynasore or genistein (Supplementary Fig. S5c). Strikingly, all three inhibitors caused a significant decrease in the proportion of cells that took up exosomes as quantified by flow-cytometry; the decrease was $97.7 \%$ with dynasore, $66.5 \%$ with phenylarsine oxide and $76.0 \%$ with genistein. Thus, the effect was most marked toxicity was detected by XTT assay after $48 \mathrm{~h}$ of transfection with siRNA. e Quantification of oA $\beta$ transfer in presence of TSG101 or VPS4A siRNA in both coverslip and transwell co-culture model by flow cytometry, shows that both siRNAs significantly inhibit oA $\beta$ transfer. Values are expressed as percentage of siRNA negative control and indicated as dotted line. Values are the mean \pm SEM $(n=4$ separate cultures), $* p<0.05, * * p<0.01, * * * p<0.001$ by two-tailed unpaired Student's $t$ tests with Welch's correction

with dynasore treatment, which almost completely abolished the uptake of exosomes (Fig. 5a), while having only minor effect on the internalization of oA $\beta$ added directly to the medium (Fig. 5b). This observation supports that the uptake of exosomes, and thus also oAß transferred via this route, is regulated by dynamin.

The dependence on dynamin, and thus exosomes, for the spread of oAß between neurons was further confirmed using dSH-SY5Y cells in the transwell model using donor cells fed with exosomes, isolated from conditioned media (oA $\beta$-AF700 treated raSH-SY5Y cells). In this setting with an absence of direct neuritic connections, oA $\beta$ transfer was almost completely blocked by dynamin inhibition (Fig. 5c), in line with a major dependence on exosomes for transfer. When instead performing the same experiment using the coverslip co-culture model, allowing for direct cell-to-cell contacts, there was also a significant decrease of transferred oAß (Fig. 5c). Since our observations substantiate the hypothesis that exosomes play a significant role in transferring oA $\beta$ from one neuron to another, we next sought to investigate whether transfer of exosomes containing oA $\beta$ had any direct toxic effect on the recipient cells. Cell-tocell transfer of exosomes, isolated from conditioned media 

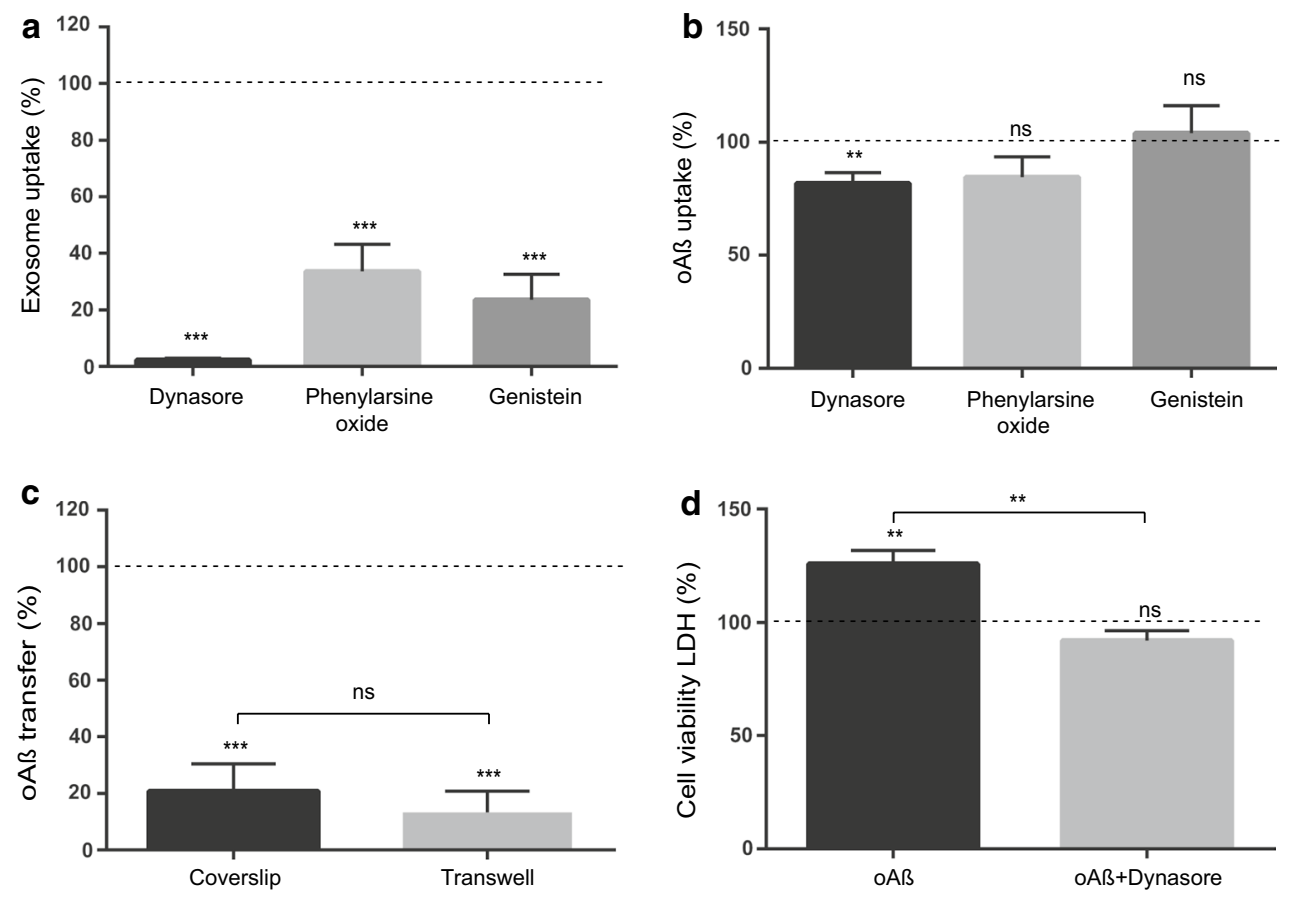

Fig. 5 The uptake of exosomes and the subsequent spreading of oAß is dynamin-dependent. a, b Uptake of PKH67 labelled exosomes or oA $\beta-A F 700$ in dSH-SY5Y cells. Cells were pre-incubated with the indicated inhibitors for $30 \mathrm{~min}$, then exposed to exosomes or oA $\beta$-AF700. After $3 \mathrm{~h}$ incubation, samples were collected and the proportion of cells with uptake was quantified by flow cytometry and related to untreated control (dotted line). c Flow cytometry analysis of oA $\beta$ transfer in presence of dynasore in coverslip and transwell co-culture models. After dynasore treatment there is a sig-

nificant decrease of the proportion of cells with oA $\beta$ transfer in both models (control, dotted line). d Transfer of exosomes isolated from oA $\beta$ treated cells causes cytotoxicity in recipient cells compared to untreated control as shown by LDH assay, whereas dynasore treatment significantly reduces the cytotoxic effect versus untreated control (dotted line). Data are represented as the mean \pm SEM, NS, not significant; $n=4 ; * * p<0.01, * * * p<0.001$ by two-tailed unpaired Student's $t$ tests with Welch's correction

(oA $\beta$-AF700 treated raSH-SY5Y cells), showed a significant increase in cellular toxicity of $26 \%$ in the recipient cell, as evident by LDH assay (Fig. 5d). Exosomes from untreated raSH-SY5Y cells had no significant toxic effect on the recipient cells (Supplementary Fig. S5a). Importantly, we found that such induced toxicity could be abolished by blocking the transfer of exosomes using dynasore (Fig. 5d). These data provide proof-of-concept that the transfer of exosomes and oA $\beta$ together with subsequent toxicity, can be prevented by inhibiting the dynamin-dependent uptake pathway.

\section{Discussion}

Recent evidence suggests that toxic $\mathrm{A} \beta$ aggregates can spread pathology in the Alzheimer brain. The nature of the propagating species has not been established, although several studies have indicated a particularly pathogenic role of soluble $\mathrm{oA} \beta$ on synaptic and cellular functions and structure $[13,32,50,60]$. It has been speculated that exosomes might transfer neurodegenerative proteins in the affected brain [28]. Accordingly, exosomes from blood [22], CSF [17, 49] and

cell cultures [46] have been shown to contain monomeric $\mathrm{A} \beta$ and tau, but so far, no study has addressed the presence of oA $\beta$ in exosomes from human AD brains. In this study, we could show that $\mathrm{AD}$ brain exosomes contain an increased amount of oA $\beta$ compared to non-neurological control brains and found evidence that exosomes can be responsible for the neuron-to-neuron transfer of toxic oA $\beta$. These findings suggest that exosomes might be the main mediator of the pathogenic progression in $\mathrm{AD}$ as was recently suggested for dementia with Lewy bodies [41]. In addition, we found a co-localization between oA $\beta$ and exosomes inside neurons, which might indicate that exosomes play a role in $\mathrm{A} \beta$ sorting and oligomerization [16]. The AD brain exosomes were further shown to effectively transfer $\mathrm{oA} \beta$ from one neuron to another, with subsequent toxic effects on the recipient cells. Interestingly, at least a part of the exosomes seems to be transferred intact to further cells, consistent with a recent study showing that a substantial fraction of exosomes internalized in one cell were subsequently passed on to a second cell [44]. Importantly, there is increasing evidence of correlations between intra-neuronal oA $\beta$ and cell death [43]. We have previously demonstrated that transfer of oA $\beta$ causes 
neurotoxicity [40] which has also been shown with $A ß$ containing exosomes isolated from AD CSF [33]. Accordingly, we now found signs of neurotoxicity both morphologically and with the LDH and the XTT assays after transfer of exosomes carrying oA $\beta$. This observation not only reinforces the role of intracellular oA $\beta$ in $\mathrm{AD}$ pathogenesis but also establishes the disease relevance associated with the exosomal neuron-to-neuron transfer of intercellular oA $\beta$.

The molecular content of exosomes is a fingerprint of the releasing cell type and, because of their small size, neuronal exosomes are released into accessible body fluids such as blood and CSF [48]. Since neuronal exosomes display unique neuron-specific surface markers $[22,26]$ they may be a valuable biomedical marker for early diagnosis and treatment in $\mathrm{AD}$. Indeed, exosomes have recently been highlighted as diagnostic biomarkers in various disease conditions, including $\mathrm{AD}[29,36]$. In concordance, the finding of increased levels of oA $\beta$ in brain exosomes opens the possibility that similar features could be detected also in easily accessible body fluids, such as plasma and CSF. Hence, measurement of increased oA $\beta$ in exosomes from such patient samples could potentially serve as a diagnostic tool.

The intercellular propagation of oA $\beta$ and its ensuing toxicity could also serve as a potential treatment target by inhibiting either formation, secretion, or cellular uptake of exosomes. Indeed, downregulation of TSG101 and VPS4A, proteins necessary for exosome formation and secretion, was found to result in decreased release of exosomes and a reduced subsequent transfer of $\mathrm{oA} \beta$, thus supporting the possibility of modulating this mechanism. Moreover, these observations are in line with recent studies showing that interfering with exosome release can impact the release of specific proteins $[9,14]$. An alternative therapeutic target could be the dynamin-dependent uptake of exosomes [23, $24]$ as the dynamin inhibitor dynasore decreased exosome propagation, spread of $\mathrm{oA} \beta$ and the associated neuronal toxicity, leading to rescued cell viability. Dynasore itself would not be a feasible therapeutic substance, but phenothiazinederived antipsychotic drugs have been suggested to inhibit dynamin dependent endocytosis [11] and could thus be suitable for further drug development.

In conclusion, our results point to a role for exosomes in the spreading of toxic $\mathrm{oA} \beta$ and the associated disease progression in the AD brain (summarized in Supplementary Fig. S6). It has been suggested that exosomal release may provide an alternative disposal mechanism to lysosomal degradation of oA $\beta$ [5] or other proteins that are resistant to degradation [55]. We speculate that this alternative mechanism of clearance, which initially could be beneficial for the cells, over time becomes a liability with increased propagation of pathological proteins throughout the brain. The possibility of inhibiting exosome transfer and the related spread and toxicity of oA $\beta$ may lead to the identification of new pharmaceutical targets for AD.

Acknowledgements The authors like to thank Dr. Anna Falk for the kind gift of the AF22 cells, MSc. Chris Sackmann for the kind gift of the CD63-GFP SH-SY5Y cells and Dr. Jakob Domert for expert illustrations. Xandra Breakefield is acknowledged for critical proofreading of the manuscript. This research was made possible by funding from the Swedish Research Council (MH: 523-2013-2735), The Swedish Alzheimer foundation, The Swedish Brain Foundation, the Hans-Gabriel and Alice Trolle-Wachtmeister Foundation for Medical Research, Konung Gustaf V:s och Drottning Victorias Frimurarestiftelse, Marianne and Marcus Wallenberg Foundation, The Swedish Fund for Research without Animal Experiments, The Swedish Dementia Foundation, the Linköping University Neurobiology Centre and the County Council of Östergötland. The funders had no role in study design, data collection and analysis, decision to publish, or preparation of the manuscript.

Author contributions MSS and AA designed the experimental approach, performed all the major biochemical and cellular experiments, analysed and interpreted the data, generated the figures, participated in the study design, and in writing the manuscript. LC carried out SEC and DOT blot, prepared the $\mathrm{A} \beta$ aggregates and participated in writing the manuscript. $\mathrm{CH}$ prepared brain slices and carried out immunohistochemistry and participated in writing the manuscript. ML carried out EM and participated in writing the manuscript. LA provided antibodies and participated in writing the manuscript. MI provided brain samples and participated in writing the manuscript. $\mathrm{MH}$ conceived the hypothesis, coordinated, and led the study, participated in study design, data interpretation and in writing the manuscript.

\section{Compliance with ethical standards}

Conflict of interest The authors have declared that no conflict of interest exists.

Open Access This article is distributed under the terms of the Creative Commons Attribution 4.0 International License (http://creativeco mmons.org/licenses/by/4.0/), which permits unrestricted use, distribution, and reproduction in any medium, provided you give appropriate credit to the original author(s) and the source, provide a link to the Creative Commons license, and indicate if changes were made.

\section{References}

1. Agholme L, Lindstrom T, Kagedal K, Marcusson J, Hallbeck M (2010) An in vitro model for neuroscience: differentiation of SHSY5Y cells into cells with morphological and biochemical characteristics of mature neurons. J Alzheimers Dis 20:1069-1082. https://doi.org/10.3233/JAD-2010-091363

2. Agholme L, Nath S, Domert J, Marcusson J, Kagedal K, Hallbeck M (2013) Proteasome inhibition induces stress kinase dependent transport deficits-implications for Alzheimer's disease. Mol Cell Neurosci 58C:29-39. https://doi.org/10.1016/j.mcn.2013.11.001

3. Akrap I, Thavamani A, Nordheim A (2016) Vps4A-mediated tumor suppression upon exosome modulation? Ann Transl Med 4:180. https://doi.org/10.21037/atm.2016.04.18

4. Asai H, Ikezu S, Tsunoda S, Medalla M, Luebke J, Haydar T, Wolozin B, Butovsky O, Kügler S, Ikezu T (2015) Depletion of microglia and inhibition of exosome synthesis halt tau propagation. Nat Neurosci. https://doi.org/10.1038/nn.4132 
5. Bellingham SA, Guo BB, Coleman BM, Hill AF (2012) Exosomes: vehicles for the transfer of toxic proteins associated with neurodegenerative diseases? Front Physiol 3:124. https://doi. org/10.3389/fphys.2012.00124

6. Blockhuys S, Celauro E, Hildesjo C, Feizi A, Stal O, Fierro-Gonzalez JC, Wittung-Stafshede P (2017) Defining the human copper proteome and analysis of its expression variation in cancers. Metallomics 9:112-123. https://doi.org/10.1039/c6mt00202a

7. Braak H, Braak E (1991) Neuropathological staging of Alzheimerrelated changes. Acta Neuropathol 82:239-259

8. Brettschneider J, Del Tredici K, Lee VM, Trojanowski JQ (2015) Spreading of pathology in neurodegenerative diseases: a focus on human studies. Nat Rev Neurosci 16:109-120. https://doi. org/10.1038/nrn3887

9. Bulloj A, Leal MC, Xu H, Castano EM, Morelli L (2010) Insulindegrading enzyme sorting in exosomes: a secretory pathway for a key brain amyloid-beta degrading protease. J Alzheimers Dis 19:79-95. https://doi.org/10.3233/JAD-2010-1206

10. Cosker KE, Segal RA (2014) Neuronal signaling through endocytosis. Cold Spring Harb Perspect Biol. https://doi.org/10.1101/ cshperspect.a020669

11. Daniel JA, Chau N, Abdel-Hamid MK, Hu L, von Kleist L, Whiting A, Krishnan S, Maamary P, Joseph SR, Simpson F et al (2015) Phenothiazine-derived antipsychotic drugs inhibit dynamin and clathrin-mediated endocytosis. Traffic 16:635-654. https://doi. org/10.1111/tra.12272

12. Danzer KM, Kranich LR, Ruf WP, Cagsal-Getkin O, Winslow AR, Zhu L, Vanderburg CR, McLean PJ (2012) Exosomal cell-tocell transmission of alpha synuclein oligomers. Mol Neurodegener 7:42. https://doi.org/10.1186/1750-1326-7-42

13. DeKosky ST, Scheff SW (1990) Synapse loss in frontal cortex biopsies in Alzheimer's disease: correlation with cognitive severity. Ann Neurol 27:457-464. https://doi.org/10.1002/ana.41027 0502

14. Dinkins MB, Dasgupta S, Wang G, Zhu G, Bieberich E (2014) Exosome reduction in vivo is associated with lower amyloid plaque load in the 5XFAD mouse model of Alzheimer's disease. Neurobiol Aging 35:1792-1800. https://doi.org/10.1016/j.neuro biolaging.2014.02.012

15. Domert J, Rao SB, Agholme L, Brorsson AC, Marcusson J, Hallbeck M, Nath S (2014) Spreading of amyloid-beta peptides via neuritic cell-to-cell transfer is dependent on insufficient cellular clearance. Neurobiol Dis. https://doi.org/10.1016/j. nbd.2013.12.019

16. Edgar JR, Willen K, Gouras GK, Futter CE (2015) ESCRTs regulate amyloid precursor protein sorting in multivesicular bodies and intracellular amyloid-beta accumulation. J Cell Sci 128:2520-2528. https://doi.org/10.1242/jcs.170233

17. Eitan E, Hutchison ER, Marosi K, Comotto J, Mustapic M, Nigam SM, Suire C, Maharana C, Jicha GA, Liu D et al (2016) Extracellular vesicle-associated abeta mediates trans-neuronal bioenergetic and $\mathrm{Ca} 2+$-handling deficits in alzheimer's disease models. NPJ Aging Mech Dis. https://doi.org/10.1038/npjam d.2016.19

18. Eitan E, Suire C, Zhang S, Mattson MP (2016) Impact of lysosome status on extracellular vesicle content and release. Ageing Res Rev 32:65-74. https://doi.org/10.1016/j.arr.2016.05.001

19. Englund H, Sehlin D, Johansson A-SS, Nilsson LN, Gellerfors P, Paulie S, Lannfelt L, Pettersson FE (2007) Sensitive ELISA detection of amyloid-beta protofibrils in biological samples. J Neurochem 103:334-345. https://doi.org/10.111 1/j.1471-4159.2007.04759.x

20. Falk A, Koch P, Kesavan J, Takashima Y, Ladewig J, Alexander M, Wiskow O, Tailor J, Trotter M, Pollard S et al (2012) Capture of neuroepithelial-like stem cells from pluripotent stem cells provides a versatile system for in vitro production of human neurons.
PLoS One 7:e29597. https://doi.org/10.1371/journal.pone.00295 97

21. Fevrier B, Raposo G (2004) Exosomes: endosomal-derived vesicles shipping extracellular messages. Curr Opin Cell Biol 16:415421. https://doi.org/10.1016/j.ceb.2004.06.003

22. Fiandaca MS, Kapogiannis D, Mapstone M, Boxer A, Eitan E, Schwartz JB, Abner EL, Petersen RC, Federoff HJ, Miller BL et al (2015) Identification of preclinical Alzheimer's disease by a profile of pathogenic proteins in neurally derived blood exosomes: a case-control study. Alzheimers Dement 11(600-607):e601. https ://doi.org/10.1016/j.jalz.2014.06.008

23. Fitzner D, Schnaars M, van Rossum D, Krishnamoorthy G, Dibaj P, Bakhti M, Regen T, Hanisch UK, Simons M (2011) Selective transfer of exosomes from oligodendrocytes to microglia by macropinocytosis. J Cell Sci 124:447-458. https://doi. org/10.1242/jcs.074088

24. Fruhbeis C, Frohlich D, Kuo WP, Amphornrat J, Thilemann S, Saab AS, Kirchhoff F, Mobius W, Goebbels S, Nave KA et al (2013) Neurotransmitter-triggered transfer of exosomes mediates oligodendrocyte-neuron communication. PLoS Biol 11:e1001604. https://doi.org/10.1371/journal.pbio.1001604

25. Fu H, Hussaini SA, Wegmann S, Profaci C, Daniels JD, Herman M, Emrani S, Figueroa HY, Hyman BT, Davies P et al (2016) 3D Visualization of the temporal and spatial spread of tau pathology reveals extensive sites of tau accumulation associated with neuronal loss and recognition memory deficit in aged tau transgenic mice. PLoS One. https://doi.org/10.1371/journal.pone.0159463

26. Goetzl EJ, Boxer A, Schwartz JB, Abner EL, Petersen RC, Miller BL, Kapogiannis D (2015) Altered lysosomal proteins in neural-derived plasma exosomes in preclinical Alzheimer disease. Neurology 85:40-47. https://doi.org/10.1212/WNL.0000000000 001702

27. Gouras G, Tampellini D, Takahashi R, Capetillo-Zarate E (2010) Intraneuronal beta-amyloid accumulation and synapse pathology in Alzheimer's disease. Acta Neuropathol 119:523-541. https:// doi.org/10.1007/s00401-010-0679-9

28. Guo JL, Lee VM (2014) Cell-to-cell transmission of pathogenic proteins in neurodegenerative diseases. Nat Med 20:130-138. https://doi.org/10.1038/nm.3457

29. Hamlett ED, Goetzl EJ, Ledreux A, Vasilevko V, Boger HA, LaRosa A, Clark D, Carroll SL, Carmona-Iragui M, Fortea J et al (2016) Neuronal exosomes reveal Alzheimer's disease biomarkers in Down syndrome. Alzheimers Dement. https://doi.org/10.1016/j. jalz.2016.08.012

30. Hasegawa T, Konno M, Baba T, Sugeno N, Kikuchi A, Kobayashi M, Miura E, Tanaka N, Tamai K, Furukawa K et al (2011) The AAA-ATPase VPS4 regulates extracellular secretion and lysosomal targeting of alpha-synuclein. PLoS One 6:e29460. https://doi. org/10.1371/journal.pone.0029460

31. Horikoshi Y, Sakaguchi G, Becker AG, Gray AJ, Duff K, Aisen PS, Yamaguchi H, Maeda M, Kinoshita N, Matsuoka Y (2004) Development of Abeta terminal end-specific antibodies and sensitive ELISA for Abeta variant. Biochem Biophys Res Commun 319:733-737. https://doi.org/10.1016/j.bbrc.2004.05.051

32. Hsia AY, Masliah E, McConlogue L, Yu GQ, Tatsuno G, Hu K, Kholodenko D, Malenka RC, Nicoll RA, Mucke L (1999) Plaqueindependent disruption of neural circuits in Alzheimer's disease mouse models. Proc Natl Acad Sci USA 96:3228-3233

33. Joshi P, Turola E, Ruiz A, Bergami A, Libera DD, Benussi L, Giussani P, Magnani G, Comi G, Legname G et al (2014) Microglia convert aggregated amyloid- $\beta$ into neurotoxic forms through the shedding of microvesicles. Cell Death Differ 21:582-593. https://doi.org/10.1038/cdd.2013.180

34. Kumari S, Mg S, Mayor S (2010) Endocytosis unplugged: multiple ways to enter the cell. Cell Res 20:256-275. https://doi. org/10.1038/cr.2010.19 
35. Lane RE, Korbie D, Anderson W, Vaidyanathan R, Trau M (2015) Analysis of exosome purification methods using a model liposome system and tunable-resistive pulse sensing. Sci Rep 5:7639. https ://doi.org/10.1038/srep07639

36. Logozzi M, De Milito A, Lugini L, Borghi M, Calabro L, Spada M, Perdicchio M, Marino ML, Federici C, Iessi E et al (2009) High levels of exosomes expressing CD63 and caveolin-1 in plasma of melanoma patients. PLoS One 4:e5219. https://doi. org/10.1371/journal.pone.0005219

37. Maas SLN, De Vrij J, Broekman MLD (2014) Quantification and size-profiling of extracellular vesicles using tunable resistive pulse sensing. Jove-J Vis Exp. https://doi.org/10.3791/51623

38. McLean CA, Cherny RA, Fraser FW, Fuller SJ, Smith MJ, Vbeyreuther K, Bush AI, Masters CL (1999) Soluble pool of Abeta amyloid as a determinant of severity of neurodegeneration in Alzheimer's disease. Ann Neurol 46:860-866. https://doi.org/10.1002/1531-8249(199912)46:6\%3C860 ::AID-ANA8\%3E3.0.CO;2-M

39. Narasimhan S, Guo JL, Changolkar L, Stieber A, McBride JD, Silva LV, He Z, Zhang B, Gathagan RJ, Trojanowski JQ et al (2017) Pathological tau strains from human brains recapitulate the diversity of tauopathies in nontransgenic mouse brain. J Neurosci 37:11406-11423. https://doi.org/10.1523/JNEUR OSCI.1230-17.2017

40. Nath S, Agholme L, Kurudenkandy FR, Granseth B, Marcusson J, Hallbeck M (2012) Spreading of neurodegenerative pathology via neuron-to-neuron transmission of beta-amyloid. J Neurosci 32:8767-8777. https://doi.org/10.1523/JNEUR OSCI.0615-12.2012

41. Ngolab J, Trinh I, Rockenstein E, Mante M, Florio J, Trejo M, Masliah D, Adame A, Masliah E, Rissman RA (2017) Brainderived exosomes from dementia with Lewy bodies propagate $\alpha$-synuclein pathology. Acta Neuropathol Commun 5:46. https:// doi.org/10.1186/s40478-017-0445-5

42. Perez-Gonzalez R, Gauthier SA, Kumar A, Levy E (2012) The exosome secretory pathway transports amyloid precursor protein carboxyl-terminal fragments from the cell into the brain extracellular space. J Biol Chem 287:43108-43115. https://doi. org/10.1074/jbc.M112.404467

43. Pigino G, Morfini G, Atagi Y, Deshpande A, Yu C, Jungbauer L, LaDu M, Busciglio J, Brady S (2009) Disruption of fast axonal transport is a pathogenic mechanism for intraneuronal amyloid beta. Proc Natl Acad Sci USA 106:5907-5912. https://doi. org/10.1073/pnas.0901229106

44. Polanco J, Li C, Durisic N, Sullivan R, Götz J (2018) Exosomes taken up by neurons hijack the endosomal pathway to spread to interconnected neurons. Acta Neuropathol Commun 6:10. https ://doi.org/10.1186/s40478-018-0514-4

45. Raj A, Kuceyeski A, Weiner M (2012) A network diffusion model of disease progression in dementia. Neuron 73:1204-1215. https ://doi.org/10.1016/j.neuron.2011.12.040

46. Rajendran L, Honsho M, Zahn TR, Keller P, Geiger KD, Verkade P, Simons K (2006) Alzheimer's disease beta-amyloid peptides are released in association with exosomes. Proc Natl Acad Sci USA 103:11172-11177. https://doi.org/10.1073/pnas.0603838103

47. Saheki Y, De Camilli P (2012) Synaptic vesicle endocytosis. Cold Spring Harb Perspect Biol 4:a005645. https://doi.org/10.1101/ cshperspect.a005645

48. Salido-Guadarrama I, Romero-Cordoba S, Peralta-Zaragoza O, Hidalgo-Miranda A, Rodriguez-Dorantes M (2014) MicroRNAs transported by exosomes in body fluids as mediators of intercellular communication in cancer. Onco Targets Ther 7:13271338. https://doi.org/10.2147/OTT.S61562

49. Saman S, Kim W, Raya M, Visnick Y, Miro S, Saman S, Jackson B, McKee AC, Alvarez VE, Lee NC et al (2012) Exosomeassociated tau is secreted in tauopathy models and is selectively phosphorylated in cerebrospinal fluid in early Alzheimer disease. J Biol Chem 287:3842-3849. https://doi.org/10.1074/jbc. M111.277061

50. Selkoe DJ (2008) Soluble oligomers of the amyloid beta-protein impair synaptic plasticity and behavior. Behav Brain Res 192:106-113. https://doi.org/10.1016/j.bbr.2008.02.016

51. Stokin GB, Lillo C, Falzone TL, Brusch RG, Rockenstein E, Mount SL, Raman R, Davies P, Masliah E, Williams DS et al (2005) Axonopathy and transport deficits early in the pathogenesis of alzheimer's disease. Science 307:1282-1288. https://doi. org/10.1126/science. 1105681

52. Thal DR, Rub U, Orantes M, Braak H (2002) Phases of a betadeposition in the human brain and its relevance for the development of AD. Neurology 58:1791-1800. https://doi.org/10.1212/ WNL.58.12.1791

53. Thal DR, Rub U, Schultz C, Sassin I, Ghebremedhin E, Del Tredici K, Braak E, Braak H (2000) Sequence of Abeta-protein deposition in the human medial temporal lobe. J Neuropathol Exp Neurol 59:733-748. https://doi.org/10.1093/jnen/59.8.733

54. Thery C, Amigorena S, Raposo G, Clayton A (2006) Isolation and characterization of exosomes from cell culture supernatants and biological fluids. Curr Protoc Cell Biol 3:22. https://doi. org/10.1002/0471143030.cb0322s30

55. Thery C, Zitvogel L, Amigorena S (2002) Exosomes: composition, biogenesis and function. Nat Rev Immunol 2:569-579. https ://doi.org/10.1038/nri855

56. Tucker S, Moller C, Tegerstedt K, Lord A, Laudon H, Sjodahl J, Soderberg L, Spens E, Sahlin C, Waara ER et al (2015) The murine version of BAN2401 (mAb158) selectively reduces amyloid-beta protofibrils in brain and cerebrospinal fluid of tg-ArcSwe mice. J Alzheimers Dis 43:575-588. https://doi.org/10.3233/JAD140741

57. Tucker S, Möller C, Tegerstedt K, Lord A, Laudon H, Sjödahl J, Söderberg L, Spens E, Sahlin C, Waara ER et al (2015) The murine version of BAN2401 (mAb158) selectively reduces amyloid- $\beta$ protofibrils in brain and cerebrospinal fluid of tg-ArcSwe mice. JAD 43:575-588. https://doi.org/10.3233/JAD-14074 1

58. Urbanelli L, Magini A, Buratta S, Brozzi A, Sagini K, Polchi A, Tancini B, Emiliani C (2013) Signaling pathways in exosomes biogenesis, secretion and fate. Genes (Basel) 4:152-170. https:// doi.org/10.3390/genes4020152

59. Vella LJ, Hill AF, Cheng L (2016) Focus on extracellular vesicles: exosomes and their role in protein trafficking and biomarker potential in alzheimer's and parkinson's disease. Int J Mol Sci 17:173. https://doi.org/10.3390/ijms17020173

60. Walsh DM, Klyubin I, Fadeeva JV, Cullen WK, Anwyl R, Wolfe MS, Rowan MJ, Selkoe DJ (2002) Naturally secreted oligomers of amyloid beta protein potently inhibit hippocampal longterm potentiation in vivo. Nature 416:535-539. https://doi. org/10.1038/416535a

61. Walsh DM, Selkoe DJ (2004) Deciphering the molecular basis of memory failure in Alzheimer's disease. Neuron 44:181-193. https ://doi.org/10.1016/j.neuron.2004.09.010 